\title{
ЭКОНОМИКО-МАТЕМАТИЧЕСКОЕ МОДЕЛИРОВАНИЕ
}

УДК: $332.14 ; 338.24 ; 338.27$

JEL: O38; R58; C45

\section{Целевое управление инновационным развитием регионов России}

\author{
Л. Г. Чередниченко ${ }^{1}$, Р. В. Губарев ${ }^{1}$, Е. И. Дзюба ${ }^{2,3}$, Ф. С. Файзуллин ${ }^{4}$ \\ ${ }^{1}$ Российский государственный университет им. Г. В.Плеханова, \\ Российская Федерация, 117997, Москва, пер. Стремянный, 38 \\ 2 Отделение Общероссийского народного фронта в Республике Башкортостан, \\ Российская Федерация, 450077, Уфа, ул. Кирова, 1 \\ ${ }^{3}$ Башкирское региональное отделение Российского общества «Знание», \\ Российская Федерация, 450006, Уфа, ул. Ленина, 61 \\ ${ }^{4}$ Институт социально-экономических исследований УФИЦ РАН, \\ Российская Федерация, 450054, Уфа, пр. Октября, 71
}

Для цитирования: Чередниченко Л.Г., Губарев Р. В., Дзюба Е.И., Файзуллин Ф.С. (2020) Целевое управление инновационным развитием регионов России. Вестник Санкт-Петербургского университета. Экономика. Т.36. Вып. 2. С. 319-350. https://doi.org/10.21638/spbu05.2020.207

Отставание России по уровню инновационного развития от экономически развитых стран мира обостряется в связи с активно протекающими процессами дивергенции регионов страны в данной сфере. За рубежом идет процесс трансформации трехзвенной спирали инноваций в четырехзвенную, предполагающую взаимодействие не только государства, науки, бизнес-сообщества, но и домохозяйств стран. Ключевым фактором достижения конкурентоспособности регионов экономически развитых стран мира становится развитие региональных инновационных систем за счет координации и синхронизации действий указанных акторов. Путем проведения эмпирического исследования оценивается степень дифференциации субъектов РФ по уровню инновационного развития. На основе нейромоделирования осуществляются кластеризация регионов страны (методом самоорганизующихся карт Кохонена) и прогнозирование их инновационного развития в краткосрочной перспективе путем формирования адекватного байесовского ансамбля динамических нейросетей. В результате проведенного эмпирического исследования было установлено, что в настоящее время наблюдается поляризация регионов России по уровню инновационного развития. При этом за 2015-2016 гг. произошли негативные изменения в кластерной (исходя из уровня инновационного развития) структуре субъектов РФ. В частности, существенно возросла

(c) Санкт-Петербургский государственный университет, 2020 
(с 48,8 до 66,3\%) доля российских регионов с низким и очень низким уровнем инновационного развития. Несмотря на оптимистический краткосрочный прогноз в сфере инновационного роста для большинства регионов-лидеров (Москва, Республика Татарстан и Нижегородская область) ожидается сохранение существенного «отрыва» от ряда субъектов РФ, например, Республики Башкортостан, Ярославской, Воронежской, Тульской, Калужской и Владимирской областей. Все это указывает на необходимость актуализации положений инновационной политики большинства российских регионов.

Ключевые слова: факторы инновационного развития, инновационная система, регионы России, кластеризация регионов, байесовский ансамбль нейросетей, прогнозирование инновационного развития.

\section{Введение}

Высшим руководством России одним из главных приоритетов объявлен ускоренный перевод национальной экономики на инновационную траекторию развития за счет ее цифровизации. Это призвано способствовать конвергенции российских регионов в инновационной сфере, несмотря на санкционное давление со стороны США и стран ЕС. Поэтому актуальным вопросом для экономики нашей страны остается не только оценка степени инновационности ее развития, но и оперативное выявление тенденций изменения в кратко-, средне- и долгосрочной перспективе. Это, в свою очередь, позволит своевременно актуализировать положения инновационной политики российских регионов.

В настоящее время имеется большое количество научных работ, в которых отражены авторские методики оценки развития инновационной сферы региональной экономики. Обзор применяемых подходов подробно представлен в научных статьях [Курбатова, Каган, Вшивкова, 2018; Павлова, Малютин, 2017]. Наиболее известными из них являются три тематических рейтинга: 1) инновационного развития субъектов РФ (НИУ ВШЭ); 2) инновационных регионов России (АИРР); 3) инновационного бизнеса в регионах России (РАНХиГС и АИРР).

На наш взгляд, именно «Рейтинг инновационного развития субъектов РФ», разработанный НИУ ВШЭ, по ряду причин позволяет проводить наиболее объективную оценку. Так, включенные в индекс индикаторы отвечают российским и международным статистическим стандартам, а применяемые методологические подходы соответствуют практике построения региональных инновационных индексов и формирования рейтингов под эгидой Европейской комиссии и других международных организаций. Помимо этого, такой подход характеризуется многоуровневой иерархической системой показателей.

Несмотря на множество тематических исследований, редким явлением остается применение современных информационных технологий (и прежде всего искусственного интеллекта) для кластеризации и прогнозирования уровня инновационного развития экономики на мезоуровне. Это указывает на актуальность дальнейшего развития методического аппарата таких исследований.

Основной целью статьи является обоснование и апробация авторского подхода для оценки, кластеризации и прогнозирования уровня инновационного развития субъектов РФ, предполагающего применение современных информационных технологий, а именно искусственного интеллекта. Такой подход должен способ- 
ствовать повышению эффективности принимаемых управленческих решений руководством российских регионов в инновационной сфере экономики на мезоуровне. В рамках статьи также запланирована разработка рекомендаций, направленных на развитие региональной инновационной системы на примере одного из субъектов РФ - Республики Башкортостан.

Достижение поставленных целей предполагает решение ряда задач, в соответствии с которыми необходимо: 1) уточнить основные факторы инновационного роста экономики для мезоуровня; 2) провести количественно-качественную оценку конкурентоспособности (в инновационной сфере) российских регионов в динамике за несколько лет; 3) сформировать краткосрочный прогноз развития региональных инновационных систем на примере ряда субъектов РФ; 4) выявить причины, препятствующие ускоренному выходу национальной экономики на инновационную траекторию развития; 5) разработать комплекс мер по устранению таких причин.

Цели и задачи статьи предопределили ее структуру: обзор литературы; оценка, кластеризация и прогнозирование инновационного развития субъектов РФ по авторской методике, а также направления развития региональной инновационной системы на примере Республики Башкортостан.

\section{Обзор литературы}

С учетом целей настоящего исследования представленный обзор литературы включает в себя рассмотрение четырех блоков вопросов:

1) понимания организационно-экономической природы региональной инновационной системы;

2) формирования и организации функционирования региональных инновационных систем;

3) анализа эмпирической информации в сфере организации деятельности региональных инновационных систем;

4) выявления проблем управления региональными инновационными системами, инновационным развитием регионов РФ с использованием экономикоматематического моделирования, в том числе нейронных сетей.

Первые три блока обзора литературы позволяют выявить те факторы, которые обусловливают эффективность функционирования региональных инновационных систем. Последний из них необходим для обоснования целесообразности применения нейросетевого подхода в качестве адекватного и высокоточного инструмента моделирования инновационного развития российских регионов.

В ряде эмпирических исследований (см., напр.: [Голова, Суховей, Никулина, 2017; Гохберг, 2016; Еферина и др., 2017; Земцов и др., 2016; Макаров и др., 2016]), базирующихся на статистических данных, отмечается существенная межрегиональная дифференциация регионов России по уровню инновационного развития. В частности, авторы работы [Голова, Суховей, Никулина, 2017, с.310] подчеркивают: «...Анализ динамики трансформации инновационного пространства России показывает, что в настоящее время идут достаточно интенсивные процессы затухания науки на периферии. Это создает определенные проблемы для распространения инновационных импульсов по территории страны». В результате углубля- 
ются межрегиональные дисбалансы и провоцируется отток инновационно ориентированных предпринимателей в более развитые регионы, а также формируется замкнутый круг, который в перспективе может привести к утрате экономической целостности России.

Указанные проблемы особенно остро проявляются сейчас, когда в условиях, с одной стороны, санкционного давления, а с другой - замедлившегося экономического роста, нашей стране необходимо ликвидировать (или хотя бы смягчить в ключевых для национальной безопасности областях) сильное технологическое отставание от передовых государств, наладить импортозамещающие производства [Котляров, 2016] и выйти на траекторию внедрения передовых моделей и технологий ведения хозяйственной деятельности (таких как Индустрия 4.0), основанных на инновациях.

При этом академик РАН А.Д.Некипелов отмечает наличие предпосылок для ускоренного перевода российской экономики на инновационную траекторию развития. «Сомнительно также, что произошедшие изменения в структуре производства можно однозначно считать негативными, на что намекает уничижительный термин “деиндустриализация”. И дело не только в том, что современные отрасли добывающей промышленности представляют собой сложнейшие производства, но, являясь источником спроса на высокие технологии, эти отрасли активно способствуют их интенсивной разработке (в том числе отечественным сектором НИОКР). Странным с точки зрения природы рыночной экономики является само разделение видов деятельности на прогрессивные и непрогрессивные вместо их деления на эффективные и неэффективные» [Некипелов, 2015, с. 206].

Рассмотрение основных факторов инновационного развития на мезоуровне предполагает уточнение понятийного аппарата исследования и, прежде всего, выявление сущности дефиниции «региональная инновационная система».

Концепция региональных инновационных систем (РИС) возникла в начале 1990-х гг. вследствие территориальной специализации концепции национальных (государственных) инновационных систем, разработанной К.Фриманом [Freeman, 1987] в процессе изучения технологической стратегии и экономического развития Японии. В настоящее время зарубежными учеными накоплен достаточно большой опыт в области исследования понятийного аппарата не только национальных, но и региональных инновационных систем. При этом в рамках настоящей статьи рассматриваются лишь наиболее широко распространенные определения РИС.

По мнению Д.Долорэ, региональная инновационная система является «набором взаимодействующих частных и государственных интересов, официальных институтов и организаций, осуществляющих свою деятельность в соответствии с организационной и институциональной структурой и отношениями по использованию знаний» [Doloreux, 2003, p. 82].

Другие зарубежные исследователи - П. Кук и О. Мемедович - подчеркивают разнообразие элементов РИС, понимая ее как «систему с упорядоченными внешними и внутренними связями между источниками знаний - университетами, исследовательскими центрами, посредническими структурами и институтами, оказывающими частные и государственные услуги по обеспечению инновационной деятельности, а также крупными и малыми предприятиями» [Cooke, Memedovic, 2003, p. 118]. 
Несколько иной точки зрения придерживается Б. Ашейм, который под РИС подразумевает «институциональную инфраструктуру, обеспечивающую осуществление инновационной деятельности в рамках производственной системы (структуры) региона» [Asheim, 2007, p. 233]. При этом он выделяет две подсистемы РИС: 1) производственную систему региона, состоящую из организаций; 2) региональную институциональную инфраструктуру, обеспечивающую и поддерживающую инновационную деятельность и включающую в себя финансовые институты, государственные и частные научные институты (лаборатории), ассоциации предпринимателей, высшие учебные заведения (ВУЗы), производственно-технические училища и агентства трансфера технологий [Asheim, 2007].

И наконец, К. Гунасекара в составе РИС выделяет четыре основных элемента: «Фактор региональной агломерации (кластеризации и пространственной близости предприятий); фактор региональной близости (близости элементов инфраструктуры обеспечения инновационной деятельности: квалифицированной рабочей силы, венчурного капитала, бизнес-сервисов); государственное регулирование (наличие профильных органов государственной власти); культурные нормы (принципы доверия, сотрудничества, стремления к получению новых знаний)» [Gunasekara, 2006, p. 144].

Таким образом, региональные инновационные системы описываются «как набор элементов (субъектов) инновационной деятельности и отношения между ними» [Статовский, Платонов, 2016, с. 46]. Это означает, что эффективность функционирования РИС будет определяться, во-первых, составом ее участников, и, вовторых, организацией отношений между ними. Далее кратко рассмотрены основные модели, описывающие функционирование РИС.

Представляется, что в настоящее время самой популярной моделью региональной инновационной системы является теория «тройной спирали» (triple helix theory). В названии теории отражена ее основная идея, заключающаяся в том, что инновационная система состоит из трех спиралей (государство, промышленность и наука) и связь каждой из них с двумя другими способствует их более эффективному взаимодействию [Etzkowitz, 2008].

Можно выделить уровни (стадии) сотрудничества акторов. «Модель описывает три уровня (стадии) сотрудничества: государственнический (statist), либеральный (laissez faire) и гибридный (hybrid), которые обеспечивают разный результат с точки зрения максимизации национального инновационного потенциала... государственническая и либеральная модели “тройной спирали” сдерживают инновационный потенциал страны, поскольку не обеспечивают синергетического эффекта, порождаемого тем уровнем и форматом сотрудничества, которые характерны для гибридной модели» [Разак и др., 2016, с. 47].

Развитием теории «тройной спирали» стала концепция «четверной спирали» (quadruple helix). «Данная концепция расширяет популярную парадигму тройной спирали (triple helix), указывая на то, что наряду с наукой, промышленностью и государством ключевую роль в инновационном процессе играет общество» [Караяннис, Григорудис, 2016, с. 31]. В ней «проанализирована связь между созданием знаний, инновационной активностью и повышением региональной и национальной конкурентоспособности на основе “умной специализации” (RIS3)» [Караяннис, Григорудис, 2016, с. 31]. 
В работе [Gackstatter, Kotsemir, Meissner, 2014, p. 297] отмечается, что «принцип четырехзвенной спирали повышает вероятность успешной реализации региональными политиками локально-ориентированного предпринимательского процесса, который стимулирует интенсивное экспериментаторство и изобретательство и одновременно активизирует инновационную деятельность».

С зарубежными исследованиями в части ключевых факторов развития национальных и региональных инновационных систем коррелируют и работы ряда других российских ученых. В исследовании [Юревич, 2019] указывается, что важным условием создания благоприятной инновационной экосистемы в рамках теории «четверной спирали» является высокий уровень восприимчивости домохозяйств к инновациям. Автор подчеркивает, что «это условие приобретает особую актуальность на локальном/региональном уровне из-за синергетических эффектов, возникающих в результате территориальной близости производителей и потребителей инноваций» [Юревич, 2019, с. 86]. В работе С. А. Айвазяна и М. Ю. Афанасьева в научный оборот введено понятие «инновационное пространство» как «совокупность потенциальных связей между организациями, создающими новые знания, и инновационно активными предприятиями» [Aivazian, Afanasiev, 2015, p. 11].

Важным условием инновационного развития регионов страны является создание благоприятной институциональной среды генерирования инноваций, их трансфера и диффузии [Овчинников, Кетова, 2016; Рогова, 2014]. Аналогичной точки зрения придерживаются и другие российские исследователи. Например, О.А.Романова считает, что «наиболее успешны инновации в таких странах, где само их появление связано не столько со сложившимися конкретными социальноэкономическими условиями, сколько с системой институтов, определяющих облик страны» [Романова, 2017, с. 284].

Роль институционального фактора в инновационном развитии регионов России подтверждается эмпирическими исследованиями. Так, в работе В. Н. Овчинникова и Н. П. Кетовой на примере 12 регионов из разных федеральных округов РФ статистическим методом установлено, что «формирование и развитие полноценной институционально-инновационной инфраструктуры в российской экономике является ключевым фактором, оказывающим влияние на активизацию инновационной деятельности субъектов региональной экономики» [Овчинников, Кетова, 2016, с.540]. Такие результаты подтверждаются и другими авторами [Айвазян и др., 2017; Еферина и др., 2017]. Например, «установлена зависимость между результатами инновационной активности региона и количеством потенциальных связей между научными организациями и бизнес-компаниями. Обоснована возможность использования полученного параметрического описания национальной и региональной инновационных систем для межстрановых сопоставлений» [Айвазян и др., 2017, с.29]. Другим научным коллективом эмпирическим путем было доказано, что «в долгосрочном периоде вложения в инновационную сферу дают дополнительный рост в сравнении с аналогичным объемом инвестиций в иные секторы экономики. То же справедливо и для налоговых преференций наукоемким предприятиям» [Макаров и др., 2016, с.88].

В ходе проведения эмпирического исследования С. Земцов и его соавторы подтвердили три гипотезы: «Инновационная активность в России плохо поддается эконометрическому моделированию; человеческий капитал - более важный фак- 
тор инновационной активности в России, чем затраты на исследования и разработки, ввиду их неэффективности; межрегиональный трансфер знаний оказывает влияние на инновационную активность» [Земцов и др., 2016, с. 30].

Важнейшим результатом проведенного исследования стало выявление ключевой роли человеческого капитала в создании инноваций. «Качественное и количественное наращивание человеческого капитала на $1 \%$ ведет к интенсификации инновационного выпуска и активности - в среднем на 0,5\%. В то же время увеличение различных форм финансирования на $1 \%$ приводит к росту инновационного выпуска лишь на 0,05\%, т.е. повышение затрат на инновации и разработки в регионах России со слабым человеческим капиталом не приводит к пропорционально большей результативности инновационной деятельности» [Земцов и др., 2016, с. 40]. Было установлено, что «рынок инноваций в России недостаточно развит, их финансирование неэффективно, а качество регистрируемых изобретений остается низким» [Земцов и др., 2016, с. 41].

Решением таких проблем является создание благоприятной бизнес-среды инновационно активных организаций, что подтверждает значение инновационной инфраструктуры для инновационного развития.

В макроэкономическом анализе, как правило, применяются два типа экономико-математических моделей - балансовые и факторные [Суворов, 2015]. Балансовые модели описывают процессы формирования и использования производственных ресурсов, а также балансы межотраслевых связей. В факторных моделях представлены взаимосвязи: 1) темпов и факторов экономического роста (производственные функции); 2) масштабов потребления различных благ, услуг и уровня доходов населения (функции потребительского спроса); 3) масштабов и факторов формирования внешнеторгового оборота; 4) показателей материально-вещественной и финансовой структуры национальной экономики и т.д.

Работа [Кирилюк, 2017] посвящена обзору экономико-математических моделей для исследования экономики на мезоуровне. Отмечается, что поведение социально-экономических систем адекватно описывается классическими моделями (такими как модель межотраслевого баланса Леонтьева, теоретико-игровой подход) и относительно новыми моделями, применяющими математический аппарат систем нелинейных отображений или дифференциальных уравнений, а также различными имитационными моделями.

Для имитации поведения сложных социально-экономических систем в настоящее время наиболее адекватными инструментами признаны агент-ориентированные модели. Среди российских ученых лидирующие позиции в развитии этого направления занимает коллектив исследователей из ЦЭМИ РАН (Москва) под руководством академика РАН В. Л. Макарова и член-корреспондента РАН А. Р. Бахтизина. Анализ тематической научной литературы позволяет сделать вывод о том, что и искусственные нейронные сети также являются достаточно точным инструментом для имитации поведения сложных социально-экономических систем, включая инновационные системы на макро- и мезоуровне. В частности, в работе [Корепина, Чекмарева, 2017] представлены результаты сравнительного анализа нейросетевого и агент-ориентированного подходов к моделированию сложных социально-экономических систем по ряду критериев. Исследователи отмечают высокое качество 
Таблица 1. Нейросетевое прогнозирование: преимущества и недостатки

\begin{tabular}{|c|c|}
\hline \multicolumn{2}{|c|}{ Нейросетевое прогнозирование } \\
\hline Преимущества & Недостатки \\
\hline $\begin{array}{l}\text { 1. Обеспечение адекватности нейромоделирования } \\
\text { в условиях негативного влияния триады } \\
\text { «не-факторов»: неполноты, неточности } \\
\text { и неопределенности в исходных данных. } \\
\text { 2. Способность к самообучению. Адаптация } \\
\text { синаптических весов позволяет адекватно реагировать } \\
\text { на изменения окружающей среды. } \\
\text { 3. Возможность представления достаточно } \\
\text { сложного поведения объекта (процесса) с помощью } \\
\text { иерархической структуры в рамках технологии VLSI } \\
\text { (verу-large-sсаle-integrated). } \\
\text { 4. Реализация одной из популярных парадигм } \\
\text { обучения с учителем, подразумевающей изменение } \\
\text { синаптических весов на основе набора маркированных } \\
\text { учебных примеров. В ходе такого обучения } \\
\text { нейромодель модифицирует синаптические веса для } \\
\text { минимизации расхождений между формируемым } \\
\text { сетью и желаемым выходным сигналом. } \\
\text { 5. В основу нейронных сетей положен мощный } \\
\text { математический аппарат для осуществления } \\
\text { функциональной аппроксимации любой сложности } \\
\text { с высокой степенью точности. Это, в свою очередь, } \\
\text { позволяет принимать эффективные управленческие } \\
\text { решения. }\end{array}$ & $\begin{array}{l}\text { 1. Высокая точность } \\
\text { нейромоделирования возможна при } \\
\text { условии достаточно большого массива } \\
\text { исходной информации (необходимы } \\
\text { сотни или даже тысячи наблюдений). } \\
\text { 2. Высокая трудоемкость построения } \\
\text { нейромоделей. На каждом шаге } \\
\text { формирования нейромоделей } \\
\text { исследователю необходимо принимать } \\
\text { определенные решения. Так, с целью } \\
\text { недопущения переобучения требуется } \\
\text { ограничивать количество итераций } \\
\text { (эпох) по модификации синаптических } \\
\text { весов. } \\
\text { 3. Необходимость наличия } \\
\text { специального программного } \\
\text { обеспечения и/или навыков } \\
\text { программирования. } \\
\text { 4. Низкая степень «прозрачности» } \\
\text { нейромоделей. Не представляется } \\
\text { возможным проследить процесс работы } \\
\text { таких моделей. Исследователь посылает } \\
\text { необходимые данные на вход сети } \\
\text { и получает только результат на выходе. }\end{array}$ \\
\hline
\end{tabular}

С о с т а в ле н о п о: [Аюев и др., 2015; Белолипцев и др., 2015; Букаев и др., 2001; Корепина, Чекмарева 2017; Хайкин, 2006].

прогнозирования при использовании таких подходов. Однако, несмотря на ряд преимуществ, и у нейросетевых технологий имеются недостатки (табл. 1).

В исследовании [Бахтизин, Бахтизина, 2010] отражен опыт одновременного применения агент-ориентированного и нейросетевого подходов. Авторы рассматривают методологию построения гибридных агент-ориентированных моделей с применением искусственных нейронных сетей, что позволяет преодолеть недостатки известных методов математической формализации поведения агентов микроуровня. Впоследствии такой подход был апробирован при моделировании развития экономики региона (на примере Республики Башкортостан) с учетом эффективности пространства инноваций [Макаров и др., 2016].

Искусственные нейронные сети применяются учеными-исследователями для решения прикладных экономических задач (кластеризации и прогнозирования) в качестве самостоятельного адекватного и высокоточного инструмента моделирования поведения сложных социально-экономических систем.

В работе [Романова, Сиротин, 2017] нейросетевая модель используется для распознавания технологического образа регионального металлургического комплекса, т. е. систематизации прогнозных значений параметров, определяющих этапы перепозиционирования и формирования его нового (инновационного) технологического образа. Нейромоделирование производится авторами научной статьи в программном продукте Statistika. В исследовании [Манасян, Чернов, 2013] с по- 
мощью нечеткой нейронной сети осуществляется рейтинговая оценка инновационного развития региона. Авторы разработали определенный алгоритм прогнозирования рейтинга инновационного развития региона с помощью нейросетевого подхода на основе ретроспективных динамических оценок в программном продукте Matlab.

В работах [Перова, Гончарова, 2015; Перова, Зайцева, 2017] задача кластеризации российских регионов, исходя из достигнутых результатов инновационной деятельности за определенный период времени, решается методом самоорганизующихся карт Кохонена в программных продуктах Matlab и Viscovery SOMine. B исследовании [Максименко, Новоселов, Пятковский, 2009], посвященном разработке интеллектуальной аналитической системы управления инновационным развитием региона, для оценки инновационного потенциала научно-технических организаций региона также применяется нейросетевой подход.

Таким образом, на основе тематических исследований российских и зарубежных авторов были уточнены основные факторы-драйверы, определяющие уровень инновационного развития субъектов РФ [Айвазян и др., 2017; Еферина и др., 2017; Земцов и др., 2016; Караяннис, Григорудис, 2016; Макаров и др., 2016; Овчинников, Кетова, 2016; Разак и др., 2016; Романова, 2017; Gackstatter, Kotsemir, Meissner, 2014]. К ним относятся человеческий капитал, институциональная среда, инновационная инфраструктура и различные формы господдержки бизнес-сообщества. Сочетание и взаимодействие данных факторов порождает синергетический эффект, проявляющийся в системодополняющем росте совокупного инновационного потенциала регионов России.

Очевидно, что методика оценки инновационного развития регионов России должна включать в себя эти факторы, и именно на улучшение их значений должны быть направлены программы повышения уровня инновационного развития регионов. При этом, опираясь на выводы исследований [Бахтизин, Бахтизина, 2010; Корепина, Чекмарева, 2017; Макаров и др., 2016; Максименко, Новоселов, Пятковский, 2009; Манасян, 2013; Перова, 2015; Перова, 2017; Романова, 2017], можно заключить, что искусственные нейронные сети являются современным эффективным инструментом управления (решения задачи кластеризации и прогнозирования) инновационным развитием российских регионов.

Проведенный в рамках настоящего обзора анализ исследований не является исчерпывающим по причине наличия достаточного большого количества работ. Важно отметить, что применение нейросетевого подхода, несмотря на моделирование в различных программных продуктах, позволяет адекватно решать прикладные экономические задачи с необходимой для ученого-исследователя высокой степенью точности.

\section{Оценка, кластеризация и прогнозирование инновационного развития субъектов РФ: авторская методика}

В данной статье представлен авторский подход к оценке, кластеризации и прогнозированию инновационного развития российских регионов, состоящий из трех последовательных этапов. В свою очередь, первый этап включает три подэтапа (рис. 1). 


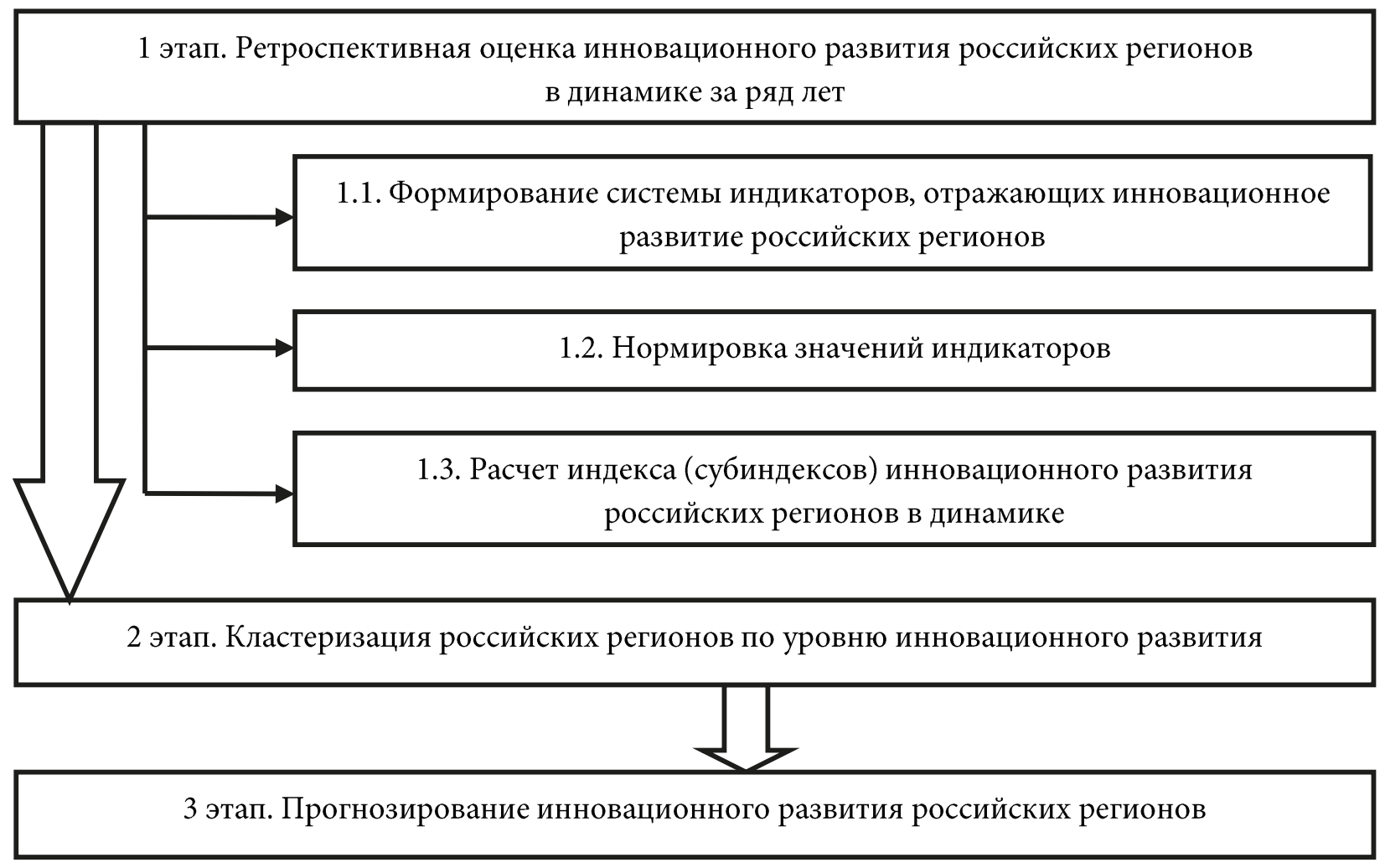

Puc. 1. Методика оценки инновационного развития регионов России

Как видно из рис. 1, на первом этапе предложенной авторами статьи методики производится ретроспективная оценка инновационного развития регионов России в динамике за ряд лет. Для этого рассчитывается индекс (субиндексы) инновационного развития субъектов РФ по данным региональной статистики.

«Ядром» представленной методики являются второй и третий этапы. В их рамках с помощью нейроматематики осуществляются соответственно кластеризация регионов страны по уровню инновационного развития и прогнозирование значения индекса в краткосрочной перспективе. На втором этапе по результатам проведенной ретроспективной оценки проводится разделение всех регионов страны на группы (кластеры) в зависимости от достигнутого количественного значения индекса (субиндексов) их инновационного развития. На третьем этапе реализуется прогностическая функция, позволяющая оценивать ожидаемое изменение уровня инновационного развития регионов страны в краткосрочной перспективе.

Кратко охарактеризуем методологические особенности авторской методики и апробируем (протестируем) ее на данных российской региональной статистики ${ }^{1}$.

1 этап. Ретроспективная оценка инновационного развития российских регионов в динамике за ряд лет. Данный этап является информационной базой для двух других этапов.

1.1. Формирование системы индикаторов, отражающих инновационное развитие российских регионов. Такая система показателей (индикаторов) в рамках исследования (табл. 2) сформирована с учетом аналитического доклада, ежегодно подготавливаемого Институтом статистических исследований и экономики зна-

${ }^{1}$ Без учета двух субъектов РФ (Республики Крым и г. Севастополя) по причине отсутствия необходимой статистической информации за 2010-2014 гг. 


\begin{tabular}{|c|c|}
\hline Наименование показателя & $\begin{array}{c}\text { Единица } \\
\text { измерения }\end{array}$ \\
\hline \multicolumn{2}{|l|}{ І. Социально-экономические условия инновационной деятельности (СЭУИД) } \\
\hline 1. Среднедушевой валовой региональный продукт (ВРП) & $\begin{array}{c}\text { тыс. } \\
\text { руб./ } 1 \text { занятый }\end{array}$ \\
\hline 2. Коэффициент ввода основных средств & $\%$ \\
\hline 3. Доля занятых с высшим образованием & $\%$ \\
\hline $\begin{array}{l}\text { 4. Численность студентов ВУЗов, обучающихся по программам бакалавриата, } \\
\text { специалитета и магистратуры }\end{array}$ & $\begin{array}{l}1 \text { чел. / } 10 \text { тыс. } \\
\text { населения }\end{array}$ \\
\hline 5. Доля организаций с широкополостным доступом в Интернет & $\%$ \\
\hline 6. Доля домашних хозяйств с доступом в Интернет & $\%$ \\
\hline \multicolumn{2}{|l|}{ II. Научно-технический потенциал (НТП) } \\
\hline $\begin{array}{l}\text { 7. Доля расходов консолидированного бюджета российского региона на } \\
\text { гражданскую науку }\end{array}$ & $\%$ \\
\hline 8. Доля (в ВРП) внутренних затрат на исследования и разработки & $\%$ \\
\hline 9. Удельные внутренние затраты на исследования и разработки & $\begin{array}{c}\text { тыс. руб. } \\
/ 1 \text { исследователь }\end{array}$ \\
\hline $\begin{array}{l}\text { 10. Средний уровень (размер сопоставляется со значением аналогичного } \\
\text { индикатора по экономике) номинальной заработной платы занятых } \\
\text { исследованиями и разработками }\end{array}$ & $\%$ \\
\hline 11. Доля молодых (возраст до 39 лет) исследователей & $\%$ \\
\hline 12. Доля исследователей с ученой степенью & $\%$ \\
\hline 13. Количество выданных на изобретения патентов & $\begin{array}{l}\text { ед./1 млн чел. } \\
\text { рабочей силы }\end{array}$ \\
\hline 14. Количество разработанных передовых производственных технологий & $\begin{array}{l}\text { ед./1 млн чел. } \\
\text { рабочей силы }\end{array}$ \\
\hline 15. Количество используемых передовых производственных технологий & $\begin{array}{l}\text { ед./1 млн чел. } \\
\text { рабочей силы }\end{array}$ \\
\hline 16. Объем поступлений от экспорта технологий & $\begin{array}{c}\text { тыс. долл. США/ } \\
\text { тыс. руб. ВРП } \\
\end{array}$ \\
\hline \multicolumn{2}{|l|}{ III. Инновационная деятельность (ИД) } \\
\hline 17. Доля организаций с технологическими инновациями & $\%$ \\
\hline 18. Доля организаций с маркетинговыми инновациями & $\%$ \\
\hline 19. Доля организаций с организационными инновациями & $\%$ \\
\hline 20. Доля организаций с экологическими инновациями & $\%$ \\
\hline $\begin{array}{l}\text { 21. Доля затрат на технологические инновации (в объеме отгруженных } \\
\text { товаров, работ и услуг) }\end{array}$ & $\%$ \\
\hline $\begin{array}{l}\text { 22. Специальные затраты, необходимые для осуществления экологических } \\
\text { инноваций }\end{array}$ & руб./1 занятый \\
\hline $\begin{array}{l}\text { 23. Доля отгруженных инновационных товаров, работ и услуг (по } \\
\text { промышленным организациям) }\end{array}$ & $\%$ \\
\hline
\end{tabular}

Примечание: на основе расчета и анализа парных коэффициентов корреляции К.Пирсона из первоначальной системы показателей были исключены два индикатора (доля занятых исследованиями и разработками и количество (на 1 млн чел. рабочей силы) поданных на изобретения патентных заявок) по причине их очень сильной связи с другими показателями (значение коэффициента превышает 0,85 , что указывает на наличие мультиколлинеарности в исходных данных). 
ний НИУ ВШЭ и посвященного анализу инновационного развития российских регионов на основе комплекса рейтинговых оценок [Гохберг, 2016]. Выбор в пользу данного тематического исследования объясняется следующими причинами. Вопервых, применяется многоуровневая иерархическая структура системы показателей российского регионального инновационного рейтинга, позволяющая не только формировать сводный индекс, но и проводить его декомпозицию на субиндексы. Во-вторых, система показателей отвечает не только российским, но и международным статистическим стандартам.

Как видно из табл. 2, в рамках настоящего исследования, по сравнению с данными работы [Гохберг, 2016], число частных показателей, характеризующих инновационное развитие регионов страны, было сокращено с 37 до 23. Основной причиной этого стало непредоставление в открытый доступ необходимой статистической информации. В частности, в системе показателей авторского исследования именно по этой причине отсутствуют шесть фиктивных или бинарных индикаторов (при наличии необходимой характеристики им присваивается значение 1 , в противном случае - 0), оценивающих нормативно-правовую базу и организационное обеспечение инновационной политики в субъектах РФ. В систему были включены индикаторы, учитывающие экологическую составляющую инновационных процессов на региональном уровне. Индикаторы (частные показатели), характеризующие инновационное развитие регионов России, имеют различные единицы измерения. Поэтому с целью обеспечения сопоставимости таких показателей проводится процедура нормализации их значений.

1.2. Нормировка значений индикаторов. Процедура осуществляется по методу «Паттерн», позволяющему объективно оценивать степень дифференциации регионов страны по каждому индикатору (частному показателю). Поскольку рост значений всех частных показателей в динамике оценивается позитивно, то применяется следующая формула:

$$
x_{i}^{\mathrm{H}}=\frac{x_{i}}{x_{i \max }},
$$

где $x_{i}-$ значение $i$-го частного показателя для каждого региона страны в определенный год; $x_{i \max }-$ наибольшее значение $i$-го частного показателя среди всех субъектов РФ в определенный год.

1.3. Расчет индекса (субиндексов) инновационного развития российских регионов в динамике за ряд лет. С целью снижения субъективности оценки расчет индекса (как и субиндексов) инновационного развития регионов страны осуществляется при условии равнозначности всех частных показателей по формуле простой средней арифметической:

$$
\text { Индекс ИР }=\frac{\sum_{i=1}^{m} x_{i}{ }^{\mathrm{H}}}{m},
$$

где Индекс ИР - индекс инновационного развития регионов страны; $m$ - количество частных показателей, характеризующих инновационное развитие регионов страны. 
Расчет осуществляется в пространственно-временном разрезе, т.е. для каждого региона страны за определенный год. В рамках исследования ограничимся расчетом индекса (субиндексов) инновационного развития субъектов РФ за 2015-2016 гг. по данным российской региональной статистики. ${ }^{2}$ Выбор периода исследования неслучаен. Начиная с 2014 г. российская экономика из-за негативного воздействия ряда внешних факторов (введения секторальных санкций США и странами ЕС в отношении ряда российских компаний, ограничивающих доступ не только к инвестиционно-финансовым ресурсам, но и к прогрессивным технологиям; обвала цен на мировых рынках энергоресурсов и т.д.) находится в зоне турбулентности. Первые негативные последствия таких факторов стали отчетливо отражаться на экономике России в 2015 г.

В табл. 3 приведены статистические величины, характеризующие инновационное развитие регионов России в 2015-2016 гг.

Таблица 3. Показатели инновационного развития регионов России, 2015-2016 гг.

\begin{tabular}{|l|c|c|c|c|c|c|c|c|}
\hline \multirow{2}{*}{\multicolumn{1}{|c|}{ Показатель }} & \multicolumn{4}{|c|}{2015 г. } & \multicolumn{4}{c|}{2016 г. } \\
\cline { 2 - 9 } & $\begin{array}{c}\text { Индекс } \\
\text { ИР }\end{array}$ & $\begin{array}{c}\text { СИ } \\
\text { СУИД }\end{array}$ & $\begin{array}{c}\text { СТ } \\
\text { НТП }\end{array}$ & СИ ИД & $\begin{array}{c}\text { Индекс } \\
\text { ИР }\end{array}$ & $\begin{array}{c}\text { СИ } \\
\text { СЭУД }\end{array}$ & $\begin{array}{c}\text { СИ } \\
\text { НТП }\end{array}$ & СИ ИД \\
\hline $\begin{array}{l}\text { Наибольшее } \\
\text { значение индекса } \\
\text { / субиндекса }\end{array}$ & 0,559 & 0,784 & 0,490 & 0,674 & 0,547 & 0,864 & 0,521 & 0,740 \\
\hline $\begin{array}{l}\text { Среднее } \\
\text { арифметическое } \\
\text { значение индекса } \\
\text { / субиндекса }\end{array}$ & 0,351 & 0,560 & 0,295 & 0,251 & 0,351 & 0,609 & 0,265 & 0,255 \\
\hline $\begin{array}{l}\text { Наименьшее } \\
\text { значение индекса } \\
\text { / субиндекса }\end{array}$ & 0,240 & 0,450 & 0,178 & 0,036 & 0,233 & 0,482 & 0,155 & 0 \\
\hline
\end{tabular}

Примечание: индекс ИР - индекс инновационного развития; СИ СЭУИД, СИ НТП, СИ ИД - субиндексы социально-экономических условий инновационной деятельности, научно-технического потенциала, инновационной деятельности соответственно.

С ост а в лен о п о: Регионы России. Социально-экономические показатели. М.: Росстат, 2017. URL: http:// www.gks.ru/wps/wcm/connect/rosstat_main/rosstat/ru/statistics/publications/catalog/doc_1138623506156 (дата обращения: 07.12.2018).

Как видно из данных табл. 3, в 2015-2016 гг. наблюдалась достаточно высокая степень дифференциации (поляризации) субъектов РФ по уровню инновационного развития: разрыв между наибольшим и наименьшим значением индекса составлял 2,3 раза. На это указывают расчет и анализ изменения в динамике не только индекса, но и субиндексов инновационного развития регионов России, характеризующих научно-технический потенциал, инновационную деятельность и ее социально-экономические условия в разных субъектах страны. Так, более значительные межрегиональные разрывы наблюдались и по научно-техническому потенциалу (наибольшее значение соответствующего субиндекса превышало наименьшее в 2,8 и 3,4 раза в 2015-2016 гг.). Несколько меньшая степень дифференциа-

${ }^{2}$ Регионы России. Социально-экономические показатели. М.: Росстат, 2017. URL: http://www. gks.ru/wps/wcm/connect/rosstat_main/rosstat/ru/statistics/publications/catalog/doc_1138623506156 (дата обращения: 07.12.2018). 
ции регионов России была зафиксирована по социально-экономическим условиям инновационной деятельности: максимальное значение соответствующего субиндекса превысило наименьшее в 1,7 раза в 2015 г. и в 1,8 раза - в 2016 г. И наконец, аномально высокие межрегиональные различия наблюдались непосредственно по инновационной деятельности. Так, наибольшее значение такого субиндекса превысило наименьшее в 18,9 и 135,9 раз, соответственно в 2015 г. и в 2016 г. Причем в 2016 г. в расчетах участвовало условно наименьшее значение, поскольку в Республике Ингушетии инновационная деятельность фактически не осуществлялась.

Можно сделать вывод о том, что конвергенция (сближение) субъектов РФ в современных условиях возможна, прежде всего, за счет «подтягивания» регионоваутсайдеров по эффективности инновационной деятельности к регионам-лидерам.

2. Кластеризация российских регионов по уровню инновационного развития. Кластеризация регионов России по уровню инновационного развития (исходя из значений не только индекса, но и субиндексов) за 2015-2016 гг. проводится методом самоорганизующихся карт Кохонена (SOM) автоматизированным способом с помощью демонстрационной версии специализированного программного продукта Deductor Studio Lite 5.1. Выбранный метод позволяет объективно (например, в отличие от теории нечетких множеств, большинство методов которой являются субъективными, поскольку базируются на суждениях экспертов) и с необходимой степенью точности группировать регионы России по уровню инновационного развития. Из-за ограниченных возможностей демонстрационной версии программного продукта такая процедура проводилась отдельно для каждого года из анализируемого периода.

Исходя из результатов ретроспективной оценки инновационного развития российских регионов, было принято решение разбить их на пять кластеров. Учитывая незначительное изменение наибольшего, наименьшего и среднего значения индекса в динамике за 2015-2016 гг. (табл. 3), субъекты РФ для 2016 г., исходя из уровня инновационного развития, объединялись также в пять кластеров. Другие основные (помимо числа кластеров) показатели и условия проводимых вычислительных экспериментов, задаваемые как автоматически, так и исследователями, представлены в табл. 4.

В ходе проведения вычислительных экспериментов для каждого года предварительно был сформирован байесовский ансамбль из пяти адекватных нейросетей Кохонена (табл. 5 и 6). Адекватной нейросетью (НС) признавалась модель, обеспечивающая стопроцентное распознавание всех объектов в процессе обучения. Другими, не менее важными, критериями адекватности нейросетей Кохонена являются максимальная и средняя ошибки обучения (оба показателя определяются автоматически в программном продукте), а также функционал качества разбиения на кластеры, который рассчитывается по следующей формуле [Белолипцев, 2015]:

$$
\Theta=\frac{1}{M} \sum_{m=1}^{M} \frac{1}{N} \sum_{i=1}^{N_{m}} d^{2}\left(\overrightarrow{x_{i m}} ; \overrightarrow{x_{ц m}}\right),
$$

где $d\left(\overrightarrow{x_{i m}} ; \overrightarrow{x_{ц m}}\right)$ - евклидово расстояние от исследуемого объекта $\overrightarrow{x_{i m}}$ до центра своего $m$-го кластера; $N_{m}$ - число объектов, попавших в $m$-й кластер. 
Таблица 4. Основные показатели и условия вычислительных экспериментов

\begin{tabular}{|l|l|}
\hline \multicolumn{1}{|c|}{ Показатель / Условие } & \multicolumn{1}{|c|}{ Коэффициент / Описание условия } \\
\hline \multicolumn{1}{|c|}{ Назначаются автоматически } \\
\hline Остановка обучения & $\begin{array}{l}\text { Обучение прекращается при выполнении } \\
\text { одного из условий: } \\
\text { 1) считать пример распознанным, если ошибка } \\
\text { составляет менее 0,05; } \\
\text { 2) по достижению 500 эпохи, или итерации. }\end{array}$ \\
\hline Параметры обучения карты Кохонена: & 20 \\
\hline $\begin{array}{l}\text { количество эпох, через которое необходимо } \\
\text { перемешивать строки }\end{array}$ & \\
\hline скорость обучения: & 0,3 \\
\hline - в начале & 0,005 \\
\hline - в конце & \\
\hline радиус обучения: & \\
\hline - в начале & \\
\hline - в конце & \\
\hline \multicolumn{2}{|c|}{ 3адаются исследователем } \\
\hline Способ начальной инициализации карты & Из обучающего множества \\
\hline Функця соседства & Гауссова функция \\
\hline
\end{tabular}

С ост а в ле н о по: данные программного продукта Deductor Studio Lite 5.1.

По смыслу функционал $\Theta$ в нашем случае - это квадрат евклидова расстояния между объектами, усредненного по объектам и кластерам. Следовательно, для повышения качества разбиения необходимо минимизировать функционал $\Theta$.

Таблица 5. Основные показатели адекватности ансамбля нейросетей Кохонена, 2015 г.

\begin{tabular}{|l|r|r|r|r|r|r|}
\hline \multicolumn{1}{|c|}{ Показатель адекватности } & HC1 & \multicolumn{1}{c|}{ HC2 } & \multicolumn{1}{c|}{ HC3 } & \multicolumn{1}{c|}{ HC4 } & \multicolumn{1}{c|}{ HC5 } \\
\hline Максимальная ошибка обучения & 0,0498 & 0,0393 & 0,0499 & 0,0393 & 0,0393 \\
\hline Средняя ошибка обучения & 0,0064 & 0,00576 & 0,00577 & 0,00638 & 0,00568 \\
\hline Распознано примеров, \% & \multicolumn{5}{|c|}{100} \\
\hline Функционал качества разбиения на кластеры & 0,065 & 0,052 & 0,061 & 0,049 & 0,060 \\
\hline
\end{tabular}

Примечание: НC1-НС5 - первая - пятая нейросети Кохонена.

С ост а в лен о по: результаты нейромоделирования в Deductor Studio Lite 5.1.

Как видно из данных табл. 5, исходя из такого показателя, как максимальная ошибка обучения, наиболее адекватными из байесовского ансамбля являются вторая, четвертая и пятая нейросети Кохонена. С учетом средней ошибки обучения предпочтительнее для решения задачи кластеризации является пятая модель. Однако, исходя из значения функционала качества разбиения на кластеры (ввиду его важности для оценки адекватности), с целью решения задачи кластеризации российских регионов по уровню инновационного развития было принято решение о применении для этого четвертой нейросети Кохонена.

Как видно из табл. 6, согласно всем основным показателям адекватности, решение задачи кластеризации российских регионов по уровню инновационного развития для 2016 г. целесообразно с помощью седьмой нейросети Кохонена. 
Таблица 6. Основные показатели адекватности ансамбля нейросетей Кохонена, 2016 г.

\begin{tabular}{|l|c|c|c|c|r|}
\hline \multicolumn{1}{|c|}{ Показатель адекватности } & HC6 & HC7 & HC8 & HC9 & HC10 \\
\hline Максимальная ошибка обучения & 0,0187 & 0,016 & 0,0187 & 0,0187 & 0,0293 \\
\hline Средняя ошибка обучения & 0,00311 & 0,00275 & 0,00346 & 0,00318 & 0,0034 \\
\hline Распознано примеров, \% & \multicolumn{5}{|c|}{100} \\
\hline Функционал качества разбиения на кластеры & 0,053 & 0,047 & 0,054 & 0,053 & 0,054 \\
\hline
\end{tabular}

Примечание: НС6-НС10 - шестая-десятая нейросети Кохонена.

С ост а в ле но п о: результаты нейромоделирования в Deductor Studio Lite 5.1.

Далее необходимо проанализировать изменение кластерной структуры российских регионов, исходя из достигнутого уровня инновационного развития (табл. 7).

Таблица 7. Зависимость кластерной структуры регионов России от уровня инновационного развития, 2015-2016 гт.

\begin{tabular}{|l|c|c|c|c|}
\hline \multirow{2}{*}{ Номер кластера } & \multicolumn{2}{|c|}{$\begin{array}{c}\text { Количество российских регионов } \\
\text { в кластере, ед. }\end{array}$} & $\begin{array}{c}\text { Удельный вес кластера, \% от общего } \\
\text { количества субтектов РФ }\end{array}$ \\
\cline { 2 - 5 } & $\mathbf{2 0 1 5}$ г. & $\mathbf{2 0 1 6}$ г. & $\mathbf{2 0 1 5}$ г. & $\mathbf{2 0 1 6}$ г. \\
\hline Первый & 6 & 5 & 7,5 & 6,3 \\
\hline Второй & 19 & 9 & 23,8 & 11,3 \\
\hline Третий & 16 & 13 & 20 & 16,3 \\
\hline Четвертый & 15 & 24 & 18,8 & 30 \\
\hline Пятый & 24 & 29 & 30 & 36,3 \\
\hline Итого & 80 & 80 & 100 & 100 \\
\hline
\end{tabular}

С оста влен о по: результаты нейромоделирования в Deductor Studio Lite 5.1.

За анализируемый период произошли негативные изменения в кластерной (по уровню инновационного развития) структуре субъектов РФ. В частности, было зафиксировано сокращение доли и числа (соответственно с 7,5 до 6,3\% и с 6 до 5) регионов страны, входящих в состав первого кластера с уровнем инновационного развития выше среднего. Также по причине уменьшения количества субъектов страны, относящихся ко второму и третьему кластерам, которые характеризуются средним и ниже среднего уровнем инновационного развития, наблюдалось сокращение удельного веса таких регионов. При этом, наоборот, возросли число и доля российских регионов, входящих в четвертый и пятый кластеры, т.е. с низким и очень низким уровнем инновационного развития. Так, если в 2015 г. удельный вес субъектов РФ, составляющих такие кластеры, достиг 48,8 \% (практически половину), то в 2016 г. - уже 66,3\%.

Таким образом, анализ кластерной структуры российских регионов позволяет сделать вывод о существенных резервах инновационного развития в современных условиях у большинства регионов страны, включая и регионы-лидеры. Относительно высокое значение индекса инновационного развития у различных регионов объясняется, как правило, лишь высокими значениями определенных субиндексов (СЭУИД, НТП или ИД). Например, в настоящее время, Республика Мордовия и Чувашская Республика (регионы - «соседи» Республики Башкортостан 
по Приволжскому федеральному округу (ПФО)) характеризуются относительно высоким уровнем локализации производства инновационной продукции и являются региональными центрами инновационной активности страны (значение субиндекса ИД составляло, соответственно, 0,589/0,651 и 0,524/0,639 в 2015-2016 гг.). Несколько иная ситуация сложилась в Томской области. Относительно высокое значение индекса инновационного развития объясняется преимущественно имеющимися социально-экономическими условиями, а не эффективностью инновационной деятельности (субиндексы СЭУИД и ИД принимали значения 0,646/0,688 и 0,348/0,395 соответственно в 2015-2016 гг.).

Из расчета и анализа изменения в динамике индекса и субиндексов инновационного развития регионов можно сделать вывод о том, что в условиях современной России по-прежнему актуальной является задача конвергенции (сближения) регионов страны по уровню инновационного развития за счет «подтягивания» отстающих субъектов РФ к центрам инновационной активности. При этом даже у регионов, имеющих высокое значение индекса инновационного развития (например, Томской области), в настоящее время имеются существенные резервы в повышении эффективности инновационной деятельности за счет более полной реализации имеющихся социально-экономических условий и научно-технического потенциала.

3. Прогнозирование инновационного развития российских регионов. В рамках данного этапа ставятся и последовательно решаются две задачи: аппроксимации данных региональной статистики и краткосрочного прогнозирования уровня инновационного развития российских регионов. Учитывая замечание о том, что ансамбль нейромоделей является более точным, чем нейросеть [Белолипцев и др., 2015], такие задачи решаются в результате формирования адекватного байесовского ансамбля динамических нейромоделей в специальном программном продукте NeuroSolutions for Excel 6.0. Основные условия нейромоделирования, задаваемые исследователем и предлагаемые программой автоматически, представлены в табл. 8.

Таблица 8. Основные условия нейромоделирования

\begin{tabular}{|c|c|}
\hline Условие & Описание условия \\
\hline Обучающая выборка & $\begin{array}{l}\text { Массив данных региональной статистики, включающий } \\
400 \text { наблюдений. Он образован из значений двух субиндексов } \\
\text { и индекса по всем субъектам РФ за 2011-2015 гг., а также } \\
\text { производных от них лаговых экзогенных и эндогенной } \\
\text { переменных, т.е. со значениями, смещенными на один год } \\
\text { назад (2010-2014 гг.). Перед обучением все наблюдения } \\
\text { «перемешиваются» }\end{array}$ \\
\hline Тестирующая выборка & $\begin{array}{l}\text { Массив данных региональной статистики, состоящий } \\
\text { из } 80 \text { наблюдений. В его состав входят значения аналогичных } \\
\text { (как и в обучающей выборке) показателей также по всем } \\
\text { регионам страны, но соответственно за } 2016 \text { и } 2015 \text { гг. }\end{array}$ \\
\hline Топология нейромоделей & Многослойный персептрон $(M L P)$ \\
\hline $\begin{array}{l}\text { Максимальное число итераций } \\
\text { (эпох) по модификации } \\
\text { синаптических весов }\end{array}$ & $\begin{array}{l}\text { Для предотвращения переобучения нейросетей (эффект } \\
\text { «бабушкиного обучения») значение показателя не превышает } \\
1000\end{array}$ \\
\hline
\end{tabular}

С ост а в ле н о по: данные программного продукта NeuroSolutions for Excel 6.0. 
Адекватной признается нейромодель при одновременном выполнении трех условий: 1) нормированная среднеквадратическая ошибка «выходной» переменной (NMSE) - менее 6\%; 2) коэффициент корреляции фактических и теоретических значений результирующего показателя $(r)$ - более 0,$97 ; 3)$ частотный критерий качества выходной переменной $\left(P^{\prime}\right)-$ свыше 80-90\%, определяемый при 5 и $8 \%$ относительной погрешности $(\varepsilon)$. Первые два показателя устанавливаются автоматически в программном продукте. Последний показатель рассчитывается самостоятельно по формуле из работы [Белолипцев, 2015].

В ходе проведения ряда вычислительных экспериментов путем последовательного добавления в нейромодели на каждом шаге одной новой входной переменной было принято решение об их спецификации (табл. 9). При этом архитектура нейромоделей оставалась постоянной: один скрытый слой, состоящий из 8 нейронов. Также не изменялся и вид активационной функции в скрытом и выходном слоях, соответственно, гиперболический тангенс и линейная.

Таблица 9. Показатели адекватности разных вариантов набора входных переменных нейромоделей

\begin{tabular}{|l|c|c|c|c|c|}
\hline Показатель & $\begin{array}{c}\text { Вариант 1 } \\
\left(\boldsymbol{X}_{\mathbf{2}}, \boldsymbol{X}_{\mathbf{4}}\right)\end{array}$ & $\begin{array}{c}\text { Вариант 2 } \\
\left(\boldsymbol{X}_{\mathbf{2}}, \boldsymbol{X}_{\mathbf{4}}, \boldsymbol{X}_{\mathbf{5}}\right)\end{array}$ & $\begin{array}{c}\text { Вариант 3 } \\
\left(\boldsymbol{X}_{\mathbf{1}}, \boldsymbol{X}_{\mathbf{2}}, \boldsymbol{X}_{\mathbf{4}}, \boldsymbol{X}_{\mathbf{5}}\right)\end{array}$ & $\begin{array}{c}\text { Вариант 4 } \\
\left(\boldsymbol{X}_{\mathbf{1}}, \boldsymbol{X}_{\mathbf{2}}, \boldsymbol{X}_{\mathbf{3}}, \boldsymbol{X}_{\mathbf{4}}, \boldsymbol{X}_{\mathbf{5}}\right)\end{array}$ & $\begin{array}{c}\text { Вариант 5 } \\
\left(\boldsymbol{X}_{\mathbf{1}}, \boldsymbol{X}_{\mathbf{2}}, \boldsymbol{X}_{\mathbf{3}}, \boldsymbol{X}_{\mathbf{4}}, \boldsymbol{X}_{\mathbf{5}}, \boldsymbol{X}_{\mathbf{6}}\right)\end{array}$ \\
\hline NMSE & 0,167 & 0,130 & 0,111 & 0,075 & 0,07 \\
\hline$r$ & 0,97 & 0,965 & 0,968 & 0,962 & 0,982 \\
\hline
\end{tabular}

С ост а влен о по: результаты нейромоделирования в NeuroSolutions for Excel 6.0.

Из данных табл. 9 видно, что пошаговое включение в нейромодель новых входных переменных приводило к снижению нормированной среднеквадратической ошибки результирующего показателя, указывающее на повышение точности аппроксимации данных региональной статистики. При этом до варианта 5 наблюдалось и уменьшение значения коэффициента корреляции между фактическими и теоретическими данными выходной переменной, что, наоборот, характеризуется негативно с позиции адекватности нейромодели. Только при варианте 5 набора входных переменных происходило одновременное снижение NMSE и увеличение $r$.

Таким образом, экспериментальным путем была уточнена спецификация нейромоделей. В нашем случае уровень инновационного развития субъектов РФ адекватно аппроксимируется нелинейной функцией:

$$
\hat{Y}=f\left(X_{1}, X_{2}, X_{3}, X_{4}, X_{5}, X_{6}\right),
$$

где $X_{2}$ и $X_{4}$ - агрегированные показатели, характеризующие значения субиндексов, соответственно, научно-технический потенциал и инновационная деятельность; $X_{1}$ и $X_{3}$ - лаговые экзогенные переменные, образованные из значений двух вышеуказанных агрегированных показателей за 2010-2015 гг.; $X_{5}$ - дополнительный входной фактор - время, рассчитывается как отношение порядкового номера текущего года к общему числу лет периода с учетом горизонта прогнозирования [Букаев, 2001]; $X_{6}$ - лаговая эндогенная переменная (значения индекса инновационного развития российских регионов за 2010-2015 гг.). 
В целях снижения NMSE проводился ряд вычислительных экспериментов, заключающихся в оптимизации числа нейронов в первом скрытом слое нейромоделей.

При этом значение нейронов во втором скрытом слое оставалось фиксированным. Критерием оптимизации становилось значение ненормализованной среднеквадратической ошибки нейросети (MSE). Согласно такому критерию, оптимальной являлась нейромодель с минимальным значением MSE.

Архитектура сформированного байесовского ансамбля динамических нейромоделей и результаты его верификации представлены в табл. 10 и 11 соответственHo.

Таблица 10. Архитектура байесовского ансамбля динамических нейромоделей

\begin{tabular}{|l|c|c|c|c|}
\hline Нейромодель & $\begin{array}{c}\text { Число } \\
\text { скрытых } \\
\text { слоев }\end{array}$ & $\begin{array}{c}\text { Варьируемое число } \\
\text { нейронов в первом } \\
\text { скрытом слое (с шагом 1) }\end{array}$ & $\begin{array}{c}\text { Оптимальное число } \\
\text { нейронов в первом } \\
\text { скрытом слое }\end{array}$ & $\begin{array}{c}\text { Фиксированное число } \\
\text { нейронов во втором } \\
\text { скрытом слое }\end{array}$ \\
\hline НСМ1 & 1 & $1 \ldots 1$ & 8 & - \\
\hline НСМ2 & 1 & $1 \ldots 1$ & 17 & - \\
\hline НСМ3 & 1 & $1 \ldots 1$ & 16 & - \\
\hline НСМ4 & 1 & $1 \ldots 11$ & 10 & - \\
\hline НСМ5 & 2 & $1 \ldots 11$ & 11 & 17 \\
\hline
\end{tabular}

Примечание: НСМ1-НСМ5 - первая-пятая нейросетевые модели.

Соста влен о по: результаты нейромоделирования в NeuroSolutions for Excel 6.0.

Как следует из табл. 10, в байесовский ансамбль были включены пять динамических нейромоделей, в том числе четыре нейросети имели один скрытый слой с дифференцированным оптимальным числом нейронов в нем.

Таблица 11. Результаты верификации байесовского ансамбля динамических нейромоделей

\begin{tabular}{|c|c|c|c|c|c|c|}
\hline \multirow{2}{*}{ Нейромодель } & \multirow{2}{*}{ NMSE } & \multirow{2}{*}{$r$} & \multicolumn{2}{|c|}{$N^{\prime}$} & \multicolumn{2}{|c|}{$P^{\prime}$} \\
\hline & & & $\varepsilon=5 \%$ & $\varepsilon=8 \%$ & $\varepsilon=5 \%$ & $\varepsilon=8 \%$ \\
\hline HCM1 & 0,036 & 0,984 & 69 & 78 & 86,3 & 97,5 \\
\hline HCM2 & 0,038 & 0,981 & 71 & 76 & 88,8 & 95,0 \\
\hline HCM3 & 0,043 & 0,982 & 67 & 74 & 83,8 & 92,5 \\
\hline HCM4 & 0,050 & 0,980 & 67 & 76 & 83,8 & 95,0 \\
\hline HCM5 & 0,053 & 0,974 & 68 & 75 & 85,0 & 93,8 \\
\hline Ансамбль нейромоделей & 0,044 & 0,980 & 68 & 76 & 85,5 & 94,8 \\
\hline
\end{tabular}

Примечание: $N^{\prime}, P^{\prime}$ - соответственно число корректно распознанных (с относительной погрешностью $\varepsilon$ ) наблюдений в тестовом множестве и частотный критерий качества выходной переменной; * ансамбль нейромоделей - значение каждого показателя рассчитывается по формуле простой средней арифметической.

С ост а в лен о по: результатам нейромоделирования в NeuroSolutions for Excel 6.0.

Данные табл. 11 дают возможность сделать вывод о сформированном адекватном байесовском ансамбле динамических нейромоделей, позволяющем с необходимой (заданной исследователями) степенью точности аппроксимировать значение индекса инновационного развития российских регионов. Учитывая тот факт, 
что в исследовании фигурируют как относительно стабильный период развития национальной экономики (2010-2013 гг. - посткризисный этап по отношению к международному финансовому кризису 2008 г.), так и период ее турбулентности (2014-2016 гг.), можно говорить и об устойчивости результатов нейромоделирования. Поэтому сформированный байесовский ансамбль динамических нейромоделей можно применить для прогнозирования уровня инновационного развития регионов России (с высокой степенью точности) в краткосрочной перспективе (на 2017 г.).

Результаты такого прогнозирования на примере российских регионов-лидеров (исходя из достигнутого уровня инновационного развития) и Республики Башкортостан представлены в табл. 12. Кратко охарактеризуем условия прогнозирования факторных и результативного показателей. Прогнозирование значений двух субиндексов (входных переменных) для каждого региона России из выборки осуществляется на основе значений их средних темпов роста за 2010-2016 гг. При этом расчеты производятся с учетом предположения о неизменности таких темпов роста показателей в краткосрочной перспективе. Прогнозное значение индекса инновационного развития субъектов РФ является средним арифметическим значением выходной переменной байесовского ансамбля динамических нейромоделей.

Таблица 12. Прогнозирование инновационного развития регионов России (по выборке) в краткосрочной перспективе (на 2017 г.)

\begin{tabular}{|l|c|c|c|c|}
\hline \multirow{2}{*}{\multicolumn{1}{|c|}{ Субъект РФ }} & \multicolumn{4}{|c|}{ Ожидаемые значения } \\
\cline { 2 - 5 } & $\boldsymbol{X}_{\mathbf{2}}$ & $\boldsymbol{X}_{\mathbf{4}}$ & $\boldsymbol{X}_{\mathbf{5}}$ & $\mathrm{Y}$ \\
\hline Москва & 0,392 & 0,577 & 1 & 0,550 \\
\hline Санкт-Петербург & 0,311 & 0,574 & 1 & 0,511 \\
\hline Республика Башкортостан & 0,358 & 0,275 & 1 & 0,407 \\
\hline Республика Татарстан & 0,297 & 0,812 & 1 & 0,564 \\
\hline Нижегородская область & 0,528 & 0,492 & 1 & 0,545 \\
\hline
\end{tabular}

Сост а в лен о по: результаты нейромоделирования в NeuroSolutions for Excel 6.0.

Как видно из табл. 12, у большинства регионов - лидеров инновационного развития страны (в 2015-2016 гг. они относились к первому кластеру) в краткосрочной перспективе ожидается рост значения индекса. Так, значение показателя должно увеличиться на $5 \%$ в Республике Татарстан, на 3,1\% - в Нижегородской области и только на 0,5\% - в Москве по сравнению с 2016 г. По Санкт-Петербургу, наоборот, в 2017 г. прогнозировалось снижение значения индекса на 2,4\% по сравнению с предыдущим годом в результате уменьшения субиндекса НТП на 4,7 \%.

Нельзя не отметить, что по-прежнему достаточно существенным должен остаться разрыв по значению индекса инновационного развития между рядом субъектов РФ, например, Республикой Башкортостан и регионами - лидерами страны. Это связано с тем, что, несмотря на достаточно благоприятные социально-экономические условия, в указанном регионе ПФО не ожидается существенного повышения эффективности инновационной деятельности в краткосрочной перспективе. Поэтому для Республики Башкортостан, как и для большинства российских регионов, в современных условиях актуализируется вопрос ускорения 
перехода региональной экономики на инновационную траекторию развития. Это означает, что большое значение имеет разработка рекомендаций по формированию региональных инновационных систем для регионов, отстающих по уровню инновационного развития.

Поэтому далее представлены направления развития инновационной деятельности в Республике Башкортостан.

\section{Направления развития региональной инновационной системы (на примере Республики Башкортостан)}

Начиная с 2012 г. Республика Башкортостан, наряду с 13 другими субъектами РФ, входит в состав Ассоциации инновационных регионов России. Однако в настоящее время инновационная инфраструктура Республики Башкортостан находится только на стадии формирования. Лишь в 5 (из 64) муниципальных образований республики созданы инновационно-ориентированные объекты, причем наблюдается их концентрация в столице региона (функционируют 15 различных объектов, включая технопарки, бизнес-инкубаторы, научные и бизнес-центры и т.д.) [Валинурова, 2016]. Необходимо отметить, что не все созданные объекты инновационной инфраструктуры являются функционирующими.

Помимо неразвитости инновационной инфраструктуры относительно регионов-лидеров, в Республике Башкортостан имеется и достаточно широкий спектр нерешенных тематических проблем:

1) несовершенство действующего законодательства, регулирующего инновационную деятельность на территории муниципальных образований. Так, в составе порядка 30 нормативно-правовых актов, применяемых на территории республики, отсутствуют документы, регулирующие вопросы венчурного инвестирования. Также нельзя не отметить и отсутствие единого терминологического аппарата, что существенно осложняет развитие процесса финансирования инновационной деятельности;

2) низкий спрос со стороны реального сектора региональной экономики на результаты научной и инновационной деятельности, наряду с ориентацией проводимых исследований на перспективные потребности новых отраслей экономики (пять из шести технологических укладов), затрудняют процесс коммерциализации таких результатов [Печаткин, 2016]. Косвенно на эту проблему указывает имеющийся дисбаланс между патентной активностью хозяйствующих субъектов и долей инновационной продукции. Если по первому показателю республика в настоящее время относится к регионам-лидерам (занимала 9-е и 11-е места по количеству выданных патентов на изобретения в расчете на 1 млн экономически активного населения в 2015-2016 гг. соответственно), то по второму показателю (удельный вес инновационной продукции в общем объеме отгружаемой покупателям продукции) ежегодно занимает более низкую позицию (находилась только на 17-м и 24-м местах в аналогичный период времени) среди 80 субъектов РФ;

3) отсутствие системы независимого мониторинга эффективности деятельности объектов республиканской инновационной инфраструктуры;

4) недостаточная господдержка малого, среднего и крупного регионального инновационного предпринимательства. В частности, в республике в настоящее 
время применяются лишь определенные элементы кластерной политики (в форме частичного субсидирования затрат на технологическое оборудование и научные исследования кластерообразующих бизнес-единиц) и точечная финансовая поддержка фундаментальных и прикладных научных исследований.

Для решения указанных проблем в Республике Башкортостан необходимо реализовать ряд мероприятий, которые можно объединить в семь блоков [Шайхутдинова, Никонова, Карачурина, 2016]:

1) формирование благоприятного инновационного климата на территории республики;

2) повышение инновационной активности населения республики;

3) финансовая господдержка крупных инновационных проектов;

4) формирование системы научно-производственной кооперации и коммерциализации инноваций;

5) развитие инновационной инфраструктуры на территории республики;

6) повышение инновационной активности малого и среднего предпринимательства республики (за счет госсодействия открытию, прежде всего, экологически чистых производств);

7) развитие информационного обеспечения инновационной деятельности.

В свою очередь, к основным направлениям реализации таких мероприятий на территории республики, на наш взгляд, следует отнести:

- совершенствование регионального законотворчества в области регулирования инновационной деятельности с учетом не только федерального, но и международного законодательства;

- формирование системы независимого мониторинга эффективности расходования бюджетных средств хозяйствующими субъектами, осуществляющими научную и инновационную деятельность;

- финансовое и налоговое стимулирование научно-технической и инновационной деятельности;

- международную технологическую интеграцию, которая в настоящее время затруднена из-за антироссийских санкций, однако существуют возможности сотрудничества с КНР, Индией и другими государствами, проводящими умеренно дружественную политику по отношению к нашей стране;

- государственно-частное партнерство (ГЧП) в сфере инновационной деятельности, что позволит привлечь частную инициативу в инновационной деятельности под прямые и/или косвенные государственные гарантии, а также будет способствовать формированию инновационной инфраструктуры.

Успешная реализация комплекса соответствующих мероприятий возможна за счет расширения целевых установок и задач региональной инновационной политики, т.е. актуализации ее положений на основе применения опыта, накопленного за пределами Республики Башкортостан - как в других регионах Российской Федерации, так и в иностранных государствах.

К такому отечественному опыту можно отнести, например, опыт Республики Татарстан и Нижегородской области - регионов-лидеров по уровню инновационного развития. В Республике Татарстан предприятия преимущественно ориенти- 
рованы на производство инновационной продукции, применяя собственные разработки. Несколько иная стратегия хозяйствующих субъектов в Нижегородской области. Она направлена на технологическое обновление путем приобретения зарубежных технологий [Агабеков, Левина, 2016].

Аналогичный вывод можно сделать, рассчитав, сопоставив и проанализировав изменение в динамике таких частных показателей инновационного развития регионов страны, как уровень выданных патентов и используемых передовых производственных технологий (определяется путем соотнесения числа выданных патентов на изобретения и используемых передовых производственных технологий с численностью экономически активного населения субъектов РФ). В 2015-2016 гг. уровень выданных патентов в Республике Татарстан был значительно выше, чем в Нижегородской области, а уровень используемых передовых производственных технологий, наоборот, был значительно выше в Нижегородской области, чем в Республике Татарстан. Вероятнее всего, если в первом регионе высокая инновационная активность хозяйствующих субъектов объясняется соответствующей собственной изобретательской активностью, то во втором регионе - активным приобретением и внедрением зарубежных технологий.

В условиях турбулентности национальной экономики по ряду объективных причин (в частности, из-за введения в отношении российских предприятий США и странами ЕС секторальных санкций, ограничивающих доступ не только к инвестиционным ресурсам, но и к прогрессивным зарубежным технологиям) для Республики Башкортостан предпочтительнее выглядит путь инновационного развития Республики Татарстан.

Согласно действующему региональному законодательству ${ }^{3}$, инновационная политика является неотъемлемой частью социально-экономической политики Республики Башкортостан. Главной целью является рост валового внутреннего продукта за счет освоения производства принципиально новых видов продукции и технологий. В настоящее время инновационная политика республики призвана обеспечить достижение, помимо главной, еще 13 основных целей. Необходимо отметить, что с момента принятия регионального закона их перечень был существенно расширен (с 6 в 2006 г. до 14, начиная с 2015 г.). Однако до сих пор в Республике Башкортостан не существует инновационной политики в форме самостоятельного документа, в отличие от ряда субъектов РФ.

Кроме того, если за разработку и утверждение социально-экономической политики в республике отвечает министерство экономического развития, то за инновационную политику - министерство промышленности и инновационной политики. Это нередко приводит к дублированию министерствами управленческих функций в ходе подготовки и утверждения вышеуказанных документов. Не добавляет целостности инновационной политике и разобщенность научно-исследовательских институтов (большинство академических учреждений являются федеральными, а отраслевые институты - региональными или частными), принимающих участие в разработке как социально-экономической, так и инновационной политики субъекта РФ.

${ }^{3}$ Закон Республики Башкортостан от 28 декабря 2006 г. № 400-3 «Об инновационной деятельности в Республике Башкортостан» (в ред. от 30 января 2015 г.), ст. 5. URL: https://base.garant. $\mathrm{ru} / 17712455 /$ (дата обращения: 15.11.2018). 
Наличие выявленных проблем указывает на недостаточно высокое качество проводимой в республике инновационной политики. Ряд задекларированных в ней положений на практике слабо реализуется. На наш взгляд, главным препятствием для достижения целей, определенных в рамках инновационной политики региона, является недостаточная проработка вопроса управленческо-организационного взаимодействия между основными акторами инновационных процессов республики (органами региональной власти, научно-исследовательскими учреждениями и бизнес-сообществом).

В связи с этим в настоящем исследовании предпринята попытка актуализации инновационной политики Республики Башкортостан путем разработки ее концептуальной модели, представленной в виде блок-схемы (рис. 2).

Представленная модель состоит из пяти взаимосвязанных блоков: координационного сектора, государственного научно-образовательного сектора, сектора негосударственных НИР и инноваций, сектора инновационной инфраструктуры и предпринимательского сектора.

В состав координационного сектора входят республиканское Правительство, Совет по научно-технической и инновационной политике в Республике Башкортостан, республиканские министерства и ведомства, участвующие в реализации политики в научной и инновационной сферах. Силами сектора разрабатываются основные цели и задачи региональной инновационной политики, регулируются процессы в ходе реализации стратегии научной и инновационной деятельности на территории республики, а также в его рамках принимаются решения о размещении госзаказа на научные исследования, направленные на экономический рост и повышение уровня национальной безопасности республики.

К государственному научно-образовательному сектору относятся государственные научно-исследовательские институты, входящие в структуру РАН и АН Республики Башкортостан, а также ведущие вузы республики. В этих организациях осуществляются фундаментальные и прикладные научные исследования и разработки для реального сектора региональной экономики. В состав сектора негосударственных НИР и инноваций входят частные научно-исследовательские институты и вузы республики, занимающиеся преимущественно прикладными исследованиями и разработками также для реального сектора республиканской экономики.

Сектор инновационной инфраструктуры образуют как материальные (технологические кластеры, технопарки, индустриальные парки, бизнес-инкубаторы и т.д.), так и нематериальные элементы (например, коммуникационные сети). Он призван содействовать реализации научных достижений в реальном секторе региональной экономики.

И, наконец, в предпринимательском секторе осуществляется выпуск инновационной продукции, реализуемой как на территории России, так и за рубежом. Он играет ключевую роль в инновационной системе Республики Башкортостан.

С организационной точки зрения для обеспечения устойчивого социальноэкономического развития муниципальных образований необходимы координация и синхронизация бизнес-процессов в научной и инновационной сферах республики. Это обусловлено тем, что в настоящее время, как правило, законопроекты в сфере региональной инновационной политики имеют «смещенный центр тяже- 


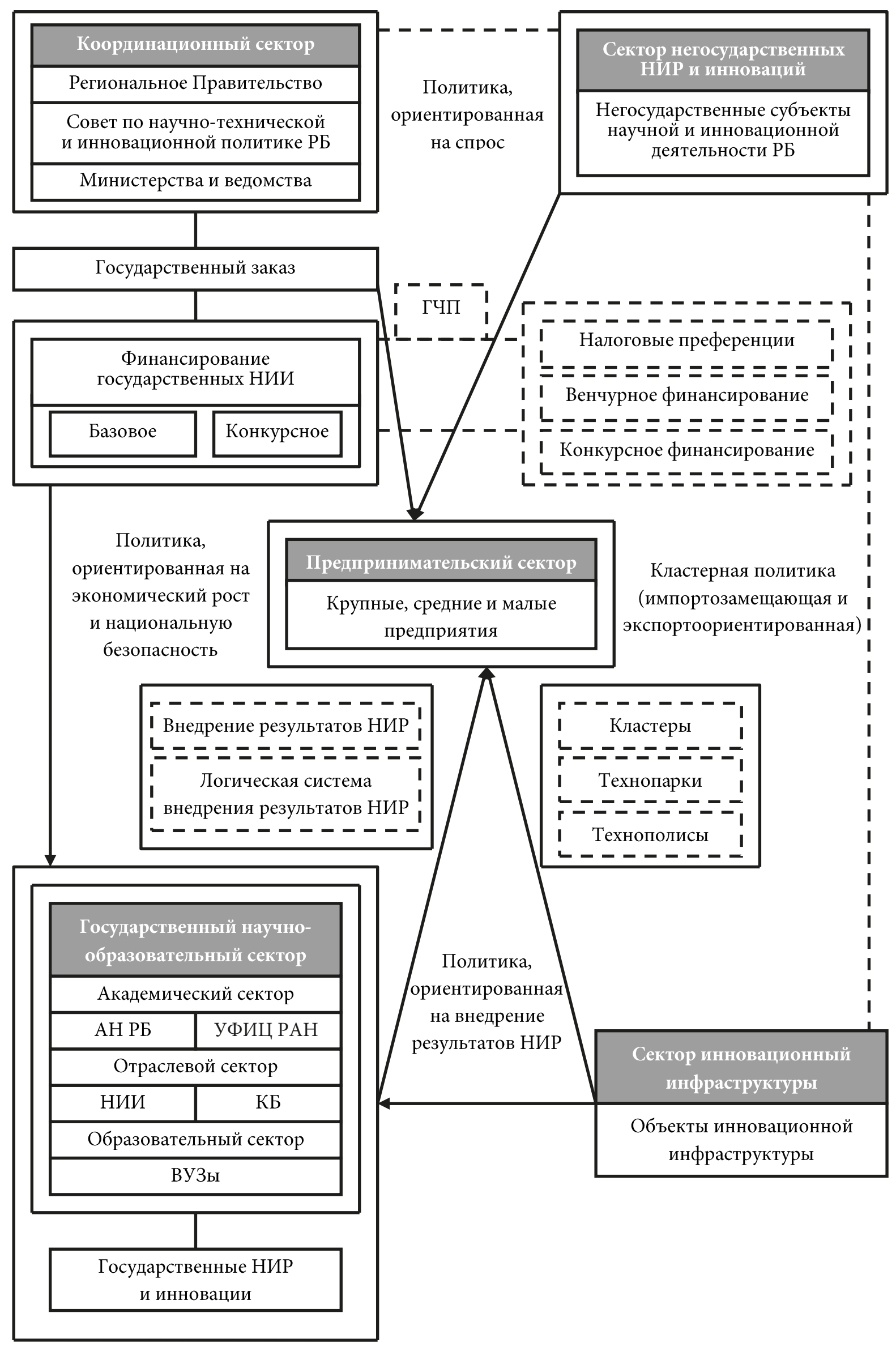

Рuc. 2. Концептуальная модель актуализированной инновационной политики РБ Сост ав лено по: [Печаткин, 2016]. 
сти» в сторону государственных научных исследований и, как следствие, бизнессектор не принимает активного участия в них.

В свою очередь, государственные научно-исследовательские учреждения продолжают работать в режиме предложения собственных разработок, слабо учитывая технологические потребности рынка и затрудняя процесс коммерциализации инновационных технологий. В итоге в настоящее время в республике слабо реализуется главная цель ее инновационной политики.

Таким образом, концептуальная модель актуализированной инновационной политики Республики Башкортостан призвана решить ряд проблем региональной инновационной системы организационно-управленческого характера, т. е. обеспечить эффективное взаимодействие государства, науки и бизнес-сообщества.

\section{Заключение}

Проведенное исследование позволило выделить ключевые факторы, способствующие инновационному развитию регионов: человеческий капитал, институциональная среда, инновационная инфраструктура и различные формы господдержки бизнес-сообщества. Система таких факторов-драйверов создает благоприятный инновационный климат на национальном и региональном уровнях. В условиях современной России, помимо научного сообщества, государства и предпринимателей, ключевую роль в инновационном процессе должны играть и домохозяйства. Это объясняется тем обстоятельством, что домохозяйства выступают конечным потребителем инноваций.

Для оценки инновационного развития регионов России в рамках исследования применялся модифицированный подход Института статистических исследований и экономики знаний НИУ ВШЭ. Принципиальными отличиями авторской методики формирования индекса являются: использование меньшего числа частных показателей, включение дополнительных индикаторов, характеризующих экологическую составляющую инновационных процессов на региональном уровне, а также применение метода «Паттерн» для нормализации значений частных показателей, позволяющего определять глубину межрегиональных «разрывов» по всей системе социально-экономических индикаторов. Отличие авторского подхода от методики, предложенной вышеуказанным институтом, заключается в возможности реализации прогностической функции. Для этого на основе ретроспективных данных региональной статистики за 2010-2016 гг. был сформирован адекватный байесовский ансамбль динамических нейросетей различной конфигурации.

В результате кластеризации, проведенной также с помощью нейроматематики (методом самоорганизующихся карт Кохонена), эмпирическим путем на основе последних данных региональной статистики была подтверждена достаточно высокая степень дифференциации субъектов РФ по уровню инновационного развития. Помимо этого, за 2015-2016 гг. произошли негативные изменения в кластерной структуре российских регионов, что определяется значениями индекса и субиндексов их инновационного развития. Так, сократилось число регионов и, как следствие, удельный вес субъектов РФ, входящих в первые три кластера, и наоборот, наблюдался рост показателей для четвертого и пятого кластеров. В частности, если 
суммарная доля регионов с низким и очень низким уровнем инновационного развития составляла порядка 48,8 \% в 2015 г., то в 2016 г. она возросла до 66,3 \%.

Несмотря на оптимистический краткосрочный прогноз в отношении 2017 г., в настоящее время в сфере инновационного развития для большинства регионов - лидеров России (Москва, Республика Татарстан и Нижегородская область) ожидается сохранение значительного отрыва от ряда субъектов РФ, например, Республики Башкортостан. Таким образом, для большинства субъектов РФ необходима актуализация инновационной политики с целью обеспечения сближения их с регионами - лидерами по уровню инновационного развития.

Учитывая роль государства в инновационном развитии на региональном уровне, в рамках исследования осуществлена актуализация положений инновационной политики на примере Республики Башкортостан. Только в этом случае будет возможна успешная реализация комплекса мероприятий, направленных на ускорение инновационного развития вышеуказанного региона. В частности, ключевой проблемой в инновационной сфере республики является низкий спрос со стороны реального сектора региональной экономики на научные исследования и разработки, что затрудняет процесс их коммерциализации, а в конечном итоге - не способствует росту объемов инновационной продукции в условиях достаточно высокой инновационной активности хозяйствующих субъектов Республики Башкортостан.

Увеличение степени реализации имеющегося у республики соответствующего потенциала позволит не только повысить конкурентоспособность Республики Башкортостан, но и будет способствовать ее вхождению в состав регионов - лидеров России по уровню инновационного развития. Очевидно, что это соответствует интересам не только Республики Башкортостан, но и Российской Федерации в целом, поскольку будет содействовать сглаживанию межрегиональных контрастов в уровнях инновационного потенциала, гармонизации территориального развития и расширению инновационной деятельности и, как следствие, росту конкурентоспособности отечественной экономики и улучшению качества жизни населения.

\section{Благодарность}

Авторы выражают благодарность А. И. Володину за ценные рекомендации при подготовке научной статьи в части проверки результатов нейромоделирования на адекватность и точность.

\section{Литература}

Агабеков С.И., Левина Е.А. (2016) Точки инновационного роста современной России на примере Приволжского федерального округа. Ars Administrandi. № 4. С. 31-44.

Айвазян С.А., Афанасьев М.Ю., Кудров В. А., Лысенкова М. А. (2017) К вопросу о параметризации национальной инновационной системы. Прикладная эконометрика. № 1. С. 29-49.

Аюев В. В., Белов Ю.С., Логинов Б. М., Логинова М.Б. (2015). Нейросетевое моделирование в NeигоSolutions. Калуга: МГТУ им. Н.Э. Баумана. 324 с.

Бахтизин А.Р., Бахтизина Н.В. (2010) Опыт построения гибридной агент-ориентированной модели с нейронными сетями. Нейрокомпьютерь: разработка, применение. № 8. С.27-39.

Белолипцев И. И., Горбатков С. А., Романов А.Н., Фархиева С.А. (2015) Моделирование управленческих решений в сфере экономики в условиях неопределенности. М.: ИНФРА-М, 299 с.

Букаев Г.И., Бублик Н.Д., Горбатков С.А., Сатаров Р.Ф. (2001) Модернизация системы налогового контроля на основе нейросетевых инбормационных технологий. М.: Наука. 344 с. 
Валинурова А.И. (2016) Проблемы формирования благоприятного инновационного климата муниципального образования Республики Башкортостан. Фундаментальные исследования. № 7. C. $76-81$.

Голова И.М., Суховей А.Ф., Никулина Н. Л. (2017) Проблемы повышения инновационной устойчивости регионального развития. Экономика региона. № 1. С. 308-318.

Гохберг Л. М. (2016) Рейтинг инновационного развития субъектов Российской Федерации. М.: НИУ ВШЭ. $248 \mathrm{c}$.

Еферина Т. В., Лизунова В.О., Просянюк Д. В., Шинова Д. А. (2017) Инновационная инфраструктура как фактор межрегиональной дифференциации в Российской Федерации. Bonpocы государственного и муниципального управления. № 1. С. 191-212.

Земцов С., Мурадов А., Уэйд И., Баринова В. (2016) Факторы инновационной активности регионов России: что важнее - человек или капитал? Форсайт. № 2. С.29-42.

Караяннис Э., Григорудис Э. (2016) Четырехзвенная спираль инноваций и «умная специализация»: производство знаний и национальная конкурентоспособность. Форсайт. № 1. С. 31-42.

Кирилюк И. Л. (2017) Экономико-математические модели для исследования мезоуровня экономики. Журнал институцииональных исследований. № 3. С. 50-63.

Корепина Т. А., Чекмарева Е. А. (2017) Нейронные сети в агент-ориентированных моделях: преимущества и недостатки гибридных методов исследования. Вопросы территориального развития. № 4. С. $1-11$.

Котляров И.Д. (2016) Локализация производства как инструмент импортозамещения. ЭКО. № 8. C. $128-140$.

Куллэ Т. А., Рогова Е. М. (2006) Партнерство государства и венчурного капитала в организации финансирования инновационного бизнеса в промышленности. Инновации. № 4. С. 58-63.

Курбатова М.В., Каган Е. С., Вшивкова А. А. (2018) Региональное развитие: проблемы формирования и реализации научно-технического потенциала. Terra Economicus. № 1. С. 101-117.

Макаров В., Айвазян С., Афанасьев М., Бахтизин А., Нанавян А. (2016) Моделирование развития экономики региона и эффективность пространства инноваций. Форсайт. № 3. С. 76-90.

Максименко А.А., Новоселов С. В., Пятковский О.И. (2009) Интеллектуальная аналитическая система управления инновационным развитием региона. Вестник Новосибирского государственного университета. Информационные технологии. № 4. С.97-107.

Манасян Н.С., Чернов В.Г. (2013) Рейтинговая оценка инновационного развития региона на основе нечеткой нейронной сети. Управление экономическими системами. № 3. URL: http://uecs.ru/ marketing/item/2013-2013-03-05-07-57-30 (дата обращения: 08.11.2018).

Некипелов А.Д. (2015) О ресурсном проклятии и его влиянии на тактику и стратегию экономического развития. Журнал новой экономической ассоциащии. № 2. С. 205-210.

Овчинников В.Н., Кетова Н.П. (2016) Системодополняющий эффект взаимодействия инновационного потенциала и институциональной среды региона. Экономика региона. № 2. С. 537-546.

Павлова И.А., Малютина А.П. (2017) Рейтинги как модель комплексной оценки инновационноинвестиционного развития экономических систем мезоуровня на примере Томской области. Вестник науки Сибири. № 2. С. 17-35.

Перова В.И., Гончарова Д. Г. (2015) Нейросетевой анализ динамики инновационной активности регионов Российской Федерации. Финансовая аналитика: проблемы и решения. № 29. С. 56-68.

Перова В.И., Зайцева К. В. (2017) Исследование динамики инновационной деятельности регионов России с применением нейросетевого моделирования. Экономический анализ: теория и практика. № 5. С. 887-901.

Печаткин В. В. (2016) Развитие инновационной системы Республики Башкортостан: проблемы и механизмы их решения. Управление экономическими системами. № 7. URL: http://uecs.ru/index. php?option=com_flexicontent\&view=items\&id=4012 (дата обращения: 08.11.2018).

Разак А.А., Роулинг М., Уайт Г., Мэйсон-Джонс Р. (2016) Управление цепочками поставок в государственном секторе: модель «тройной спирали» и координация инновационных экологических инициатив. Форсайт. № 1. С.43-52.

Рогова Е. М. (2014) Бизнес-инкубаторы как элементы системы технологического трансфера российских университетов. Инноващии. № 7. С. 53-58.

Романова О.А. (2017) Инновационная парадигма новой индустриализации в условиях формирования интегрального мирохозяйственного уклада. Экономика региона. № 1. С. 276-289.

Романова О. А., Сиротин Д. В. (2017) Образ желаемого будущего экономики индустриального региона: тенденции развития и методология оценки. Экономика региона. № 3. С. 746-763. 
Статовский Д.А., Платонов В.В. (2016) Исследование микросистем инноваций как элемента регулирования инновационной деятельности на региональном уровне. Инновации. № 11. С. 44-50.

Суворов Н. В. (2015) Актуальные направления и проблемы совершенствования модельного инструментария макроэкономического анализа. Проблемы прогнозирования. № 5. С. 25-39.

Хайкин С. (2006). Нейронные сети. М.: Вильямс. 1104 с.

Шайхутдинова Г.Ф., Никонова С.А., Карачурина Р.Ф. (2016) Стимулирование инновационной активности предпринимательства в Республике Башкортостан. Вестник УГУЭС. Наука, образование, экономика. Сер. экономика. № 2. С. 80-85.

Юревич М.А. (2019) Новые институциональные инициативы России в контексте концепции четырехзвенной инновационной спирали. Журнал институциональных исследований. № 2. С. 79-93.

Aivazian S., Afanasiev M. (2015) Assessment of innovative activity of regions in the Russian Federation. Montenegrin Journal of Economics, no. 1, pp.7-21.

Asheim B. (2007) Differentiated knowledge bases and varieties of regional innovation systems. The European Journal of Social Science, no. 20, pp. 223-241.

Cooke P., Memedovic. O. (2003) Strategies for Regional Innovation Systems: Learning Transfer and Applications. Vienna: UNIDO Policy Paper. 367 p.

Doloreux D. (2003) Regional innovation systems in the periphery: the case of the Beauce in Qubec (Canada). International Journal of Innovation Management, no. 7, pp. 67-94.

Etzkowitz H. (2008) Triple Helix Innovation: Industry, University and Government in Action. London; New York: Routledge. 168 p.

Freeman C. (1987) Technology Policy and Economic Performance: Lessons from Japan. London: Pinter Publishers. $155 \mathrm{p}$.

Gackstatter S., Kotsemir M., Meissner D. (2014) Building an Innovation-Driven Economy - The Case of BRIC and GCC Countries. Foresight, no. 4, pp. 293-308.

Gunasekara C. (2006) The generative and development roles of universities in regional innovation systems. Science and Public Policy, no. 33, pp.137-150.

Статья поступила в редакцию: 06.06.2019

Статья рекомендована в печать: 20.02.2020

Контактная информация:

Чередниченко Лариса Геннадиевна - д-р экон. наук, проф.; cherednlarisa@yandex.ru

Губарев Роман Владимирович - канд. экон. наук, доц.; gubarev.roma@yandex.ru

Дзюба Евгений Иванович - эксперт; intellectRus@yandex.ru

Файзуллин Фаниль Саитович - д-р филос. наук, проф.; fayzullin.f@gmail.com

\section{Targeted management of innovative development of Russian regions}

\section{G. Cherednichenko ${ }^{1}$, R. V. Gubarev ${ }^{1}$, E. I.Dzyuba ${ }^{2,3}$, F. S. Fayzullin ${ }^{4}$}

${ }^{1}$ Plekhanov Russian University of Economics,

36, Stremyanny per., Moscow, 117997, Russian Federation

2 All-Russia People's Front in Republic of Bashkortostan,

1, ul. Kirova, Ufa, 450077, Russian Federation

${ }^{3}$ Bashkir regional branch of the Russian society "Knowledge",

61, ul. Lenina, Ufa, 450006, Russian Federation

${ }^{4}$ Institute of Social and Economic Research of the UFRC of the RAS,

71, pr. Octyabrya, Ufa, 450054, Russian Federation

For citation: Cherednichenko L. G., Gubarev R. V., Dzyuba E.I., Fayzullin F. S. (2020) Targeted management of innovative development of Russian regions. St Petersburg University Journal of Economic Studies, vol.36, iss. 2, pp.319-350. https://doi.org/10.21638/spbu05.2020.207 (In Russian)

At present, the Russian Federation lags significantly behind the economically developed countries of the world in terms of innovative development. The situation in Russia is exacerbated 
by the active processes of divergence of the country's regions in the field of innovative development. Abroad, the process of transforming a three-tier into a four-tier spiral of innovation, involving the interaction of not only the state, science, business community, but also the civil society of the country. The key factor in achieving the competitiveness of regions of economically developed countries of the world is the development of regional innovation systems through the coordination and synchronization of actions of such actors. By conducting an empirical study, the degree of differentiation of the subjects of the Russian Federation is evaluated by the level of innovative development. Based on neuro-modeling, the regions of the country are clustering (using Kohonen's self-organizing maps) and forecasting their innovative development in the short term by forming an adequate Bayesian ensemble of dynamic neural networks. As a result of the conducted empirical research, it was established that even now the polarization of Russian regions in terms of the level of innovative development is characteristic. At the same time, in 2015-2016, there were negative changes in the cluster structure (based on the level of innovative development) of the constituent entities of the Russian Federation. So, in particular, the share of Russian regions with low and very low levels of innovative development has significantly increased (from 48,8 to 66,3\%). Despite the optimistic short-term outlook in the field of innovative development for most of the leading regions (Moscow, the Republic of Tatarstan and the Nizhny Novgorod Region), a significant "breakaway" from a number of subjects of the Russian Federation, for example, the Republic of Bashkortostan, is expected. This indicates the need to update the provisions of the innovation policy of most Russian regions.

Keywords: factors of innovative development, innovation system, Russian regions, clustering of regions, Bayesian assembly of neural network, forecast of innovation development.

\section{References}

Agabekov S.I., Levina E.A. (2016) The sources of innovative development in contemporary Russia exemplified by Volga federal district. Ars Administrandi, no. 4, pp. 31-44. (In Russian)

Aivazian S., Afanasiev M. (2015) Assessment of innovative activity of regions in the Russian Federation. Montenegrin Journal of Economics, no. 1, pp. 7-21.

Aivazian S., Afanasiev M., Kudrov A., Lysenkova M. (2017) To the question about parameterization of national innovation system. Prikladnaia ekonometrika, no. 1, pp. 29-49. (In Russian)

Asheim B. (2007) Differentiated knowledge bases and varieties of regional innovation systems. The European Journal of Social Science, no. 20, pp.223-241.

Ayuev V. V., Belov Yu. S., Loginov B. M., Loginova M. B. (2015) Neural network modeling in NeuroSolutions. Kaluga, MGTU im. N.E. Baumana. 324 p. (In Russian)

Bakhtizin A. R., Bakhtizina N. V. (2010) Hybrid agent-based models with neural networks. Neirokomp'yutery: razrabotka, primenenie, no. 8, pp. 27-39. (In Russian)

Beloliptsev I.I., Gorbatkov S. A., Romanov A. N., Farkhieva S. A. (2015) Simulation of managerial decisions in the sphere of economics under uncertainty. Moscow, INFRA-M. 299 p. (In Russian)

Bukaev G. I., Bublik N.D., Gorbatkov S. A., Satarov R.F. (2001) Modernization of the Tax Control System Based on Neural Network Information Technologies. Moscow, Nauka Publ. 344 p. (In Russian)

Carayannis E., Grigoroudis E. (2016). Quadruple Innovation Helix and Smart Specialization: Knowledge Production and National Competitiveness. Forsayt, no. 1, pp.31-41. (In Russian)

Cooke P., Memedovic. O. (2003) Strategies for Regional Innovation Systems: Learning Transfer and Applications. Vienna, UNIDO Policy Paper. 367 p.

Doloreux D. (2003) Regional innovation systems in the periphery: the case of the Beauce in Qubec (Canada). International Journal of Innovation Management, no. 7, pp. 67-94.

Eferina T. V., Lizunova V. O., Prosyanyuk D. V., Shinova D. A. (2017) Innovative infrastructure as a factor of interregional differentiation in the Russian Federation. Voprosy gosudarstvennogo i munitsipalnogo upravleniia, no. 1, pp. 191-212. (In Russian)

Etzkowitz H. (2008) Triple Helix Innovation: Industry, University and Government in Action. London, New York, Routledge. $168 \mathrm{p}$.

Freeman C. (1987) Technology Policy and Economic Performance: Lessons from Japan. London, Pinter Publishers. $155 \mathrm{p}$. 
Gackstatter S., Kotsemir M., Meissner D. (2014) Building an Innovation-Driven Economy - The Case of BRIC and GCC Countries. Foresight, no. 4, pp.293-308.

Gokhberg L. M. (2016) Russian Regional Innovation Development Rating. Moscow, NIU VSHE Publ. 248 p.

Golova I.M., Sukhovey A. F., Nikulina N.L. (2017) Problems of Increasing the Regional Development Innovative Sustainability. Ekonomika regiona, no. 1, pp.308-318. (in Russian)

Gunasekara C. (2006) The generative and development roles of universities in regional innovation systems. Science and Public Policy, no. 33, pp.137-150.

Haykin S. (2006) Neural networks. Moscow, Vil'yams Publ. 1104 p. (In Russian)

Kirilyuk I.L. (2017) Economic-mathematical models for studying of mesolevel of economy. Zhurnal institutsional'nykh issledovanii, no. 3, pp. 50-63. (In Russian)

Korepina T.A., Chekmareva E.A. (2017) Neural networks in agent-based models: advantages and disadvantages of hybrid research methods. Voprosy territorialnogo razvitiia, no.4, pp.1-11. (In Russian)

Kotlyarov I.D. (2016) Localization of production as an instrument of import substitution. ECO, no. 8, pp. 128-140. (In Russian)

Kulla T.A., Rogova E.M. (2006) The partnership between the state and venture capital in financing of innovative businesses in the industry. Innovatsii, no.4, pp. 58-63. (In Russian)

Kurbatova M. V., Kagan E.S., Vshivkova A.A. (2018) Regional development: addressing the problems of building and realization of scientific and technological capacities. Terra Economicus, no. 1, pp.101117 (In Russian)

Makarov V., Ayvazyan S., Afanasyev M., Bakhtizin A., Nanavyan A. (2016) Modeling the Development of Regional Economy and an Innovation Space Efficiency. Forsayt, no.3, pp. 76-90. (In Russian)

Maksimenko A. A., Novoselov S. V., Pyatkovskij O.I. (2009) Intellectual analytical management system of the innovational development in the regional conditio. Vestnik Novosibirskogo gosudarstvennogo universiteta. Informatsionnye tekhnologii, no. 4, pp.97-107. (In Russian)

Manasyan N.S., Chernov V.G. (2013) Rating evaluation of innovative development of the region based on the neuro-fuzzy network. Upravlenie ekonomicheskimi sistemami, no. 3. URL: http://uecs.ru/marketing/item/2013-2013-03-05-07-57-30 (accessed: 08.11.2018). (In Russian)

Nekipelov A.Dm. (2015) On the Resource Curse and its Effect on Tactics and Strategy of Economic Development. Zhurnal novoi ekonomicheskoi assotsiatsii, no.2, pp.205-210. (In Russian)

Ovchinnikov V.N., Ketova N.P. (2016) The System-Supplementing Effect of the Interaction between Innovative Capacity and Institutional Environment Factors of a Region. Ekonomika regiona, no. 2, pp. 537-546. (In Russian)

Pavlova I. A., Maliutina A. P. (2017) Rankings as a comprehensive model to assess innovation and investment development of mesolevel economic systems (case of Tomsk region). Vestnik nauki Sibiri, no. 2, pp. 1735. (In Russian)

Pechatkin V.V. (2016) Development innovation system of the Republic Of Bashkortostan: problems and ways of their solution. Upravlenie ekonomicheskimi sistemami, no.7. URL: http://uecs.ru/index. php?option=com_flexicontent\&view=items\&id=4012 (accessed: 08.11.2018). (In Russian)

Perova V.I., Goncharova D.G. (2015) The neural network analysis of trends in innovative activity of the regions of the Russian Federation. Finansovaia analitika: problemy i resheniia, no.29, pp.56-68. (In Russian)

Perova V.I., Zaitseva K.V. (2017) Researching the trends in innovation activity of Russian regions using the neural simulation. Ekonomicheskii analiz: teoriia i praktika, no. 5, pp. 887-901. (In Russian)

Razak A.A., Rowling M., White G., Mason-Jones R. (2016) Public Sector Supply Chain Management: A Triple Helix Approach to Aligning Innovative Environmental Initiatives. Forsayt, no. 1, pp.43-52. (In Russian)

Rogova E. M. (2014) Business-incubators as elements of the technological transfer of Russian universities. Innovatsii, no. 7, pp. 53-58. (In Russian)

Romanova O.A. (2017) The Innovation Paradigm of New Industrialization in the Conditions of the Integrated World Economic Way. Ekonomika regiona, no. 1, pp.276-289. (In Russian)

Romanova O.A., Sirotin D.V. (2017) The desired image of the future economy of the industrial region: development trends and evaluation methodology. Ekonomika regiona, no. 3, pp.746-763. (In Russian)

Shaikhutdinova G.F., Nikonova S.A., Karachurina R.F. (2016) Stimulation of Innovative Activity of Entrepreneurship in the Republic of Bashkortostan. Vestnik UGUES. Nauka, obrazovanie, ekonomika. Seriya ekonomika, no. 2, pp.80-85. (In Russian) 
Statovskiy D. A., Platonov V.V. (2016) The study of innovation microsystem as a part of innovation activity regulation on the regional level. Innovatsii, no. 11, pp.44-50. (In Russian)

Suvorov N. V. (2015) Current trends and problems of improving model tools of macroeconomic analysis. Problemy prognozirovaniia, no.5, pp.25-39. (In Russian)

Valinurova A. I. (2016) Problems creating a favorable climate for innovation municipalities of the Republic of Bashkortostan. Fundamental'nye issledovaniia, no. 7, pp. 76-81. (In Russian)

Yurevich M.A. (2019) Quadruple innovation helix and new institutional initiatives in Russia. Zhurnal institutsional'nykh issledovanii, no. 2, pp. 79-93. (In Russian)

Zemtsov S., Muradov A., Wade I., Barinova V. (2016) Determinants of Regional Innovation in Russia: Are People or Capital More Important? Forsayt, no. 2, pp. 29-42. (In Russian)

Received: 06.06.2019

Accepted: 20.02 .2020

Authors' information:

Larisa G. Cherednichenko - Dr. Sci. in Economics, Professor; cherednlarisa@yandex.ru Roman V.Gubarev - PhD in Economics, Associate Professor; gubarev.roma@yandex.ru Evgeniy I.Dzyuba — Expert; intellectRus@yandex.ru

Fanil' S. Fayzullin — Dr. Sci. in Philosophy, Professor; fayzullin.f@gmail.com 